\title{
MicroRNA-30a increases tight junction protein expression to suppress the epithelial-mesenchymal transition and metastasis by targeting Slug in breast cancer
}

\author{
Chia-Wei Chang ${ }^{1}$, Jyh-Cherng Yu ${ }^{2}$, Yi-Hsien Hsieh ${ }^{1}$, Chung-Chin Yao ${ }^{3}$, Jui-I Chao ${ }^{4}$, \\ Po-Ming Chen ${ }^{1}$, Hsiao-Yen Hsieh ${ }^{1}$, Chia-Ni Hsiung ${ }^{5}$, Hou-Wei Chu ${ }^{5}$, Chen-Yang \\ Shen $^{5,6}$, Chun-Wen Cheng ${ }^{1,7}$ \\ ${ }^{1}$ Institute of Biochemistry, Microbiology and Immunology, Chung Shan Medical University, Taichung, Taiwan \\ ${ }^{2}$ Department of Surgery, Tri-Service General Hospital, National Defense Medical Center, Taipei, Taiwan \\ ${ }^{3}$ Department of Surgery, Chung Shan Medical University Hospital, Taichung, Taiwan \\ ${ }^{4}$ Department of Biological Science and Technology, National Chiao Tung University, Hsinchu, Taiwan \\ ${ }^{5}$ Institute of Biomedical Sciences, Academia Sinica, Taipei, Taiwan \\ ${ }^{6}$ College of Public Health, China Medical University, Taichung, Taiwan \\ ${ }^{7}$ Clinical Laboratory, Chung Shan Medical University Hospital, Taichung, Taiwan
}

Correspondence to: Chun-Wen Cheng, e-mail: cwcheng@csmu.edu.tw Chen-Yang Shen, e-mail: bmcys@ibms.sinica.edu.tw

Keywords: breast cancer metastasis, EMT, miR-30a, slug, claudin

Received: August 07, 2015

Accepted: February 10, 2016

Published: February 24, 2016

\section{ABSTRACT}

The epithelial-to-mesenchymal (EMT) transition is a prerequisite for conferring metastatic potential during tumor progression. microRNA-30a (miR-30a) expression was significantly lower in aggressive breast cancer cell lines compared with noninvasive breast cancer and non-malignant mammary epithelial cell lines. In contrast, miR-30a overexpression reversed the mesenchymal appearance of cancer cells to result in a cobblestone-like epithelial phenotype. We identified Slug, one of the master regulators of EMT, as a target of $\mathrm{miR}-30$ a using in silico prediction. Reporter assays indicated that miR-30a could bind to the 3'-untranslted region of S/ug mRNA. Furthermore, we linked miR-30a to increased expression of claudins, a family of tight junction transmembrane proteins. An interaction between Slug and E-box in the claudin promoter sequences was reduced upon miR-30a overexpression, further leading to reduction of filopodia formation and decreased invasiveness/ metastasis capabilities of breast cancer cells. Consistently, delivery of miR-30a in xenografted mice decreased tumor invasion and migration. In patients with breast cancer, a significantly elevated risk of the miR-30a ${ }^{\text {low }} / C L D N 2^{\text {low }} /$ FSCN $^{\text {high }}$ genotype was observed, linking to a phenotypic manifestation of larger tumor size, lymph node metastasis, and advanced tumor stage among patients. In conclusion, the miR-30a/ Slug axis inhibits mesenchymal tumor development by interfering with metastatic cancer cell programming and may be a potential target for therapy in breast cancer.

\section{INTRODUCTION}

The epithelial-to-mesenchymal transition (EMT) enables tumor cells to transiently lose their epithelial features - including the loss of apico-basal polarity and disassembly of tight and adherent junctions - and acquire mesenchymal traits that lead to invasion, metastasis, and resistance to chemotherapy [1,2]. EMT is characterized by frequent, temporal, and heterogeneous changes in cellular phenotype that cannot be exclusively attributed to rigid and irreversible genetic alterations [3, 4]. Instead, the disruption of normal epigenetic mechanisms provides such 
essential flexibility, and among epigenetic mechanisms within cancer cells, post-transcriptional mechanisms involving microRNAs (miRNAs) are important in this regard.

miRNAs, which are non-coding RNAs of an average length of $22 \mathrm{nt}$, bind to the $3^{\prime}$-untranslated region (3'-UTR) of mRNAs with less-than-perfect complementarity, which results in degradation of the mRNA or repression of its translation [5]. A growing body of research has indicated that cancer cells acquire the ability to invade and disseminate via the action of dysregulated miRNAs that enhance EMT progression [6,7] and confer a selective advantage during clonal evolution $[8,9]$. Our previous breast cancer study revealed that miR-30a inhibits the invasion and migration of Hs578T and MDA-MB-231 breast cancer cells in vitro [10]. Because these two cell lines are intrinsically deficient in expression of E-cadherin [11], which is a key protein contributing to cell-cell adhesion, we hypothesized that miR-30a targets other mRNAs involved in regulating EMT.

The expansion of a tumor cell population upon overexpression of Snail family members is a prerequisite for EMT [2]. In addition, the regulator Snail (SNAI1), which mediates EMT activation for metastatic dissemination of cancer cells from the primary tumor, is targeted by miR-30a [12]. Slug (Slug) belongs to the Snail family and also triggers EMT during tumor progression [13]. We thus hypothesized that miR-30a binds to the 3'-UTR of Slug mRNA to inhibit EMTdriven invasion and migration in breast cancer. To test this hypothesis, we used an in vitro model of the mesenchymalto-epithelial transition (MET) that is regulated by the miR-30a/Slug axis. The decrease in Slug levels by miR-30a in invasive breast cancer cells resulted in a transformation to a cobblestone-like epithelial phenotype, and ectopic administration of miR-30a led to increased claudin expression, which is transcriptionally inactivated by Slug [14]. Furthermore, we proposed that miR-30a/ Slug is linked to reduced levels of fascin (FSCN gene); an actin-bundling protein localized to the tips of filopodia, and thus inhibits the development of the mesenchymal tumor phenotype in breast cancer. In addition, we used mouse xenotransplantation assays to demonstrate the effect of suppressing the miR-30a-directed repression of Slug on cancer cell progression. Moreover, our clinical analysis and experimental models demonstrate that the miR-30a/Slug axis is a potential therapeutic target in human breast cancer.

\section{RESULTS}

\section{Decreased miR-30a expression is associated with invasiveness of breast cancer cell lines}

We first assessed whether decreased miR-30a expression was significantly associated with breast cancer aggressiveness in different breast cancer cell lines. miR-30a levels were significantly decreased in highly aggressive Hs578T and MDA-MB-231 breast cancer cell lines as compared with a moderate decrease in non-invasive MCF-7 and BT-474 breast cancer cell lines and in non-malignant mammary epithelial cell lines H184B5F5/M10 and MCF-10A (Figure 1A). To examine a causal link between miR-30a expression and invasiveness in Hs578T and MDA-MB-231 cells, we created a lentiviral vector that is based on plemiR; the vector contained a 551-bp fragment of the pre-miR-30a sequence (plemiR-30a) and was expressed in Hs578T and MDA-MB-231 breast cancer cells. The plemiR-30a-transfected cell lines had $\sim 4.0$ - to 10-fold higher miR-30a amounts compared with plemiRtransfected control cells (Figure 1B). Interestingly, although both breast cancer cell lines are intrinsically deficient in E-cadherin (Figure 1C), indicating that they had lost an epithelial cell characteristic, the morphological change from an elongated and spindle-like fibroblastic shape to a cobblestone-like epithelial phenotype was observed when miR-30a was overexpressed (Figure 1D). In contrast, MCF7 breast cancer cells treated with inhibitor against miR-30a (anti-miR-30a) had enhanced tumor cell motility (Figure 1E-1G), which is considered a prerequisite for retaining metastatic potential. Thus, miR-30a may have a tumor-suppressive function to inhibit the development of the mesenchymal phenotype during EMT via an E-cadherinindependent mechanism in aggressive breast cancer cells.

\section{miR-30a targets the $3^{\prime}$-UTR of Slug mRNA}

Our initial in silico analysis using computational prediction algorithm software, including miRanda (http:// www.microrna.org/microrna/home.do), miRWalk (http:// www.umm.uni-heidelberg.de/apps/zmf/mirwalk/), and TargetScan (http://targetscan.org/) predicted that Slug mRNA may be a target of miR-30a, and Slug contains two evolutionarily conserved domains in its 3'-UTR that have complementarity with human miR-30a (Figure 2A). A dual-luciferase reporter assay showed that overexpression of miR-30a reduced the activity of the luciferase gene fused to the full-length Slug 3'-UTR (pGL4.13/Slug $3^{\prime}$-UTR/wt) by $>30 \%$ as compared with the Hs578TpcDNA3 cells (control group) $(P<0.01)$ (Figure $2 \mathrm{~B}-2 \mathrm{C}$ ). In addition, a significant reduction in luciferase activity was observed in the presence of pre-miR-30a using the reporter construct containing the Slug 3'-UTR/mut2 clone (Figure 2C). This reduction in luciferase activity was reversed by the presence of a pGL4.13 reporter construct containing mutations in the Slug $3^{\prime}$-UTR that affected either site 1 (mut1) or both site 1 and site 2 (mut3). Thus, the region from 13 to 20 is the crucial site within the 3'-UTR of Slug that is required for miR-30a binding. Moreover, Slug protein was notably repressed by $\sim 40 \%$ in plemiR-30a-transfected Hs578T and MDA-MB-231 breast cancer cells compared with cells transfected with a control construct (Figure 2D). 


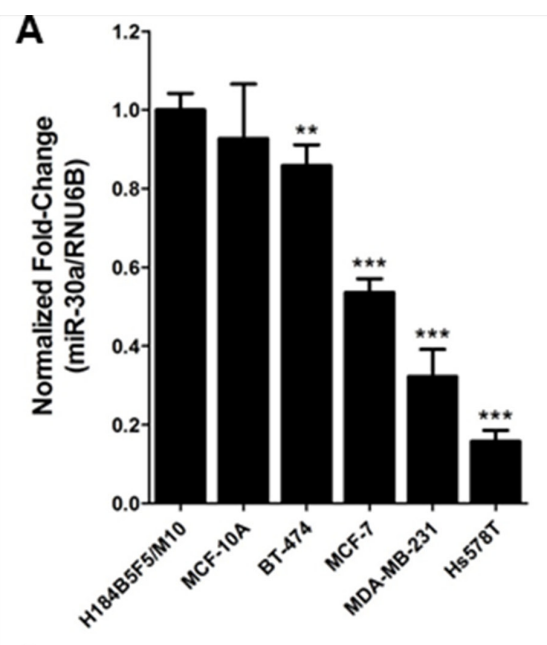

B

C
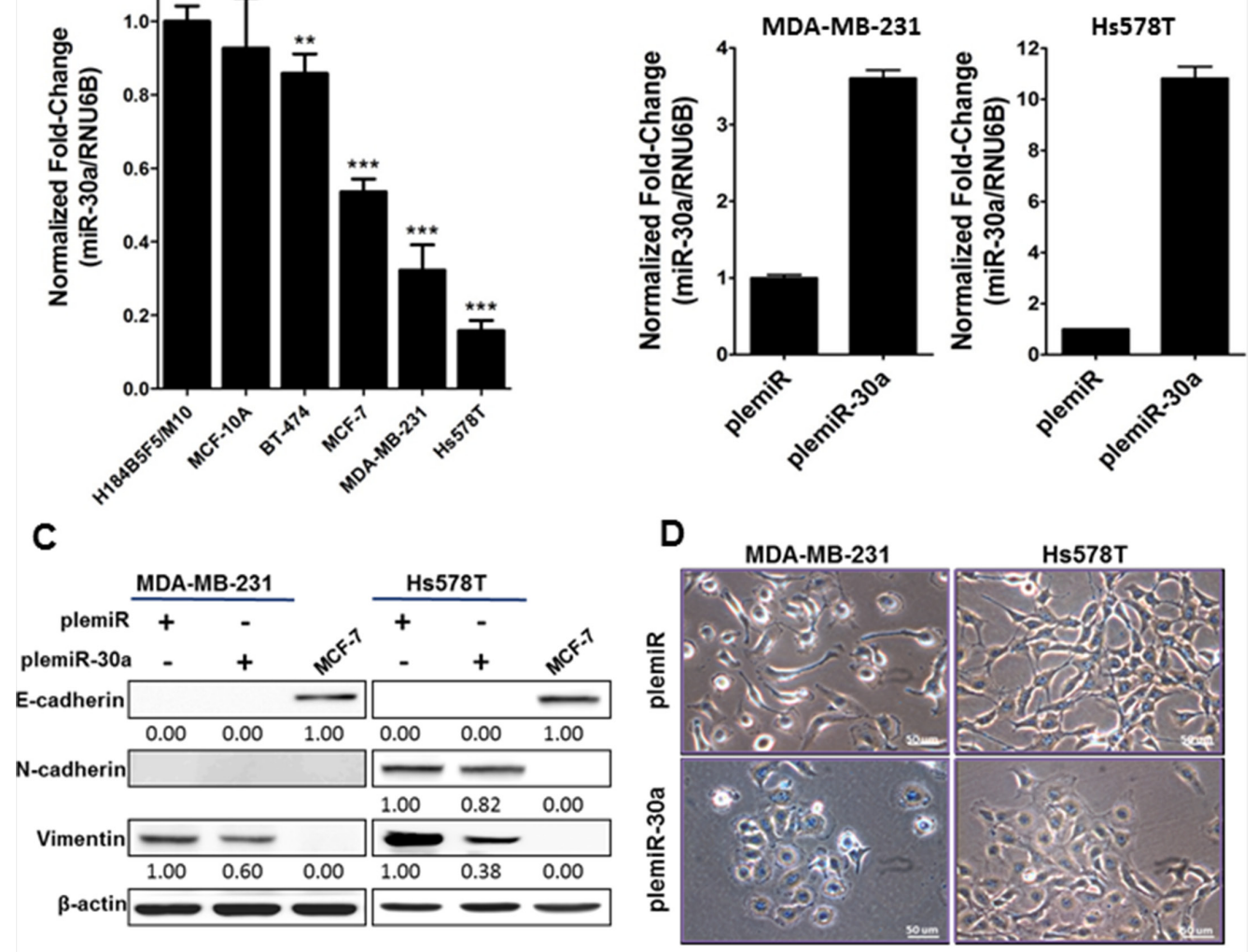

\section{E}
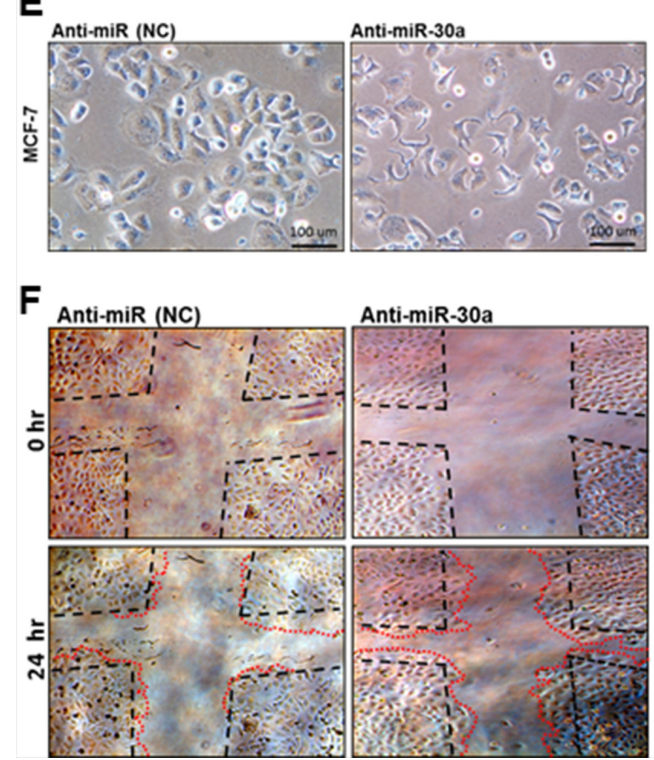

G

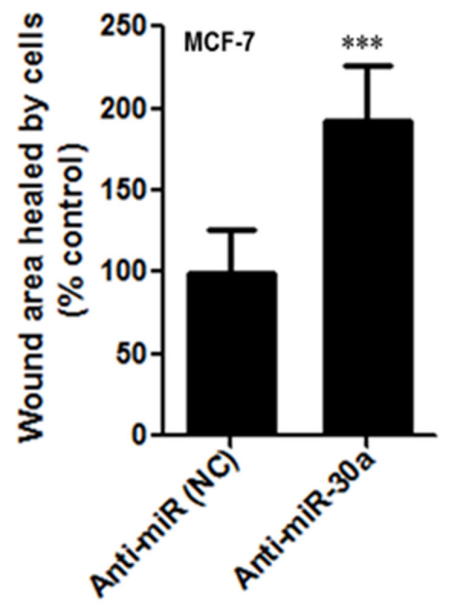

Figure 1: Decreased miR-30a levels in metastatic breast cancer. (A) Comparison of miR-30a levels among normal breast epithelial cells (H184B5F5/M10 and MCF-10A) and breast cancer cell lines that are non-metastatic (BT-474 and MCF-7) or metastatic (Hs578T and MDA-MB-231). miR-30a was quantified by TaqMan real-time PCR, and the relative levels of miR-30a were normalized to RNU6B. (B) Lentiviral transduction with plemiR-30a and subsequent miR-30a overexpression in breast cancer cell lines. miR-30a levels are expressed as the mean \pm SD from three independent experiments. (C) Western blot showing protein expression of plemiR-30a in E-cadherin-deficient breast cancer cell lines in (B), with $\beta$-actin as the loading control. (D) Representative images of the phenotypic change from mesenchymal to cobblestone-like epithelial cells in MDA-MB-231 and Hs578T cells transfected with plemiR-30a or plemiR (negative control). Scale bar $=50 \mu \mathrm{m}$. (E) Representative phenotypic change in MCF-7 cells transfected with an inhibitor against miR-30a (anti-miR-30a) and negative control (NC) (F) Representative scratch/wound healing assay images for MCF-7 cells were taken at 0 and $24 \mathrm{hr}$ after scarification. (G) Quantification of wound healing area for MCF-7 cells as in (F). Data are expressed as the mean \pm SD from triplicate experiments. ${ }^{* * *} P<0.001$ compared with the control group. 
A

SITE 1

SITE 2

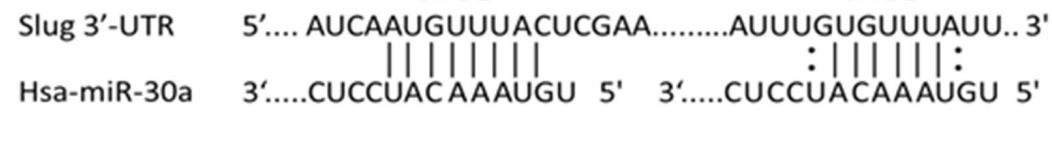

3'-UTR $1127 \mathrm{nt}$.

Slug - 12

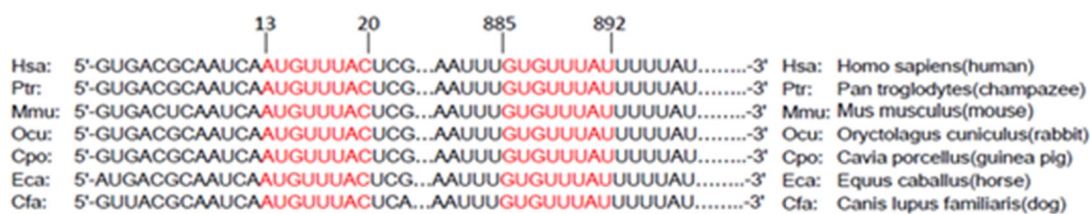

B

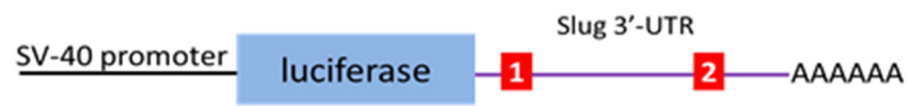

\section{SITE 1}

SITE 2

Hsa-miR-30a

Slug 3'-UTR/wt

3'.... UCCUACAAAUGU $5 '$<smiles></smiles>

3'.....UCCUACAAAUGU 5'

$:|||| \mid$ :

Slug $3^{\prime}-$ UTR/mut1 $\quad 5^{\prime}$..... TCA AACAAA TG TCGAA .......... TTT GTGTTTA TTT.... $3^{\prime}$

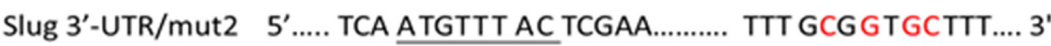

Slug 3'-UTR/mut3 5 '..... TCA AACAAA TG TCGAA ......... TTT GCG G T GCTTT.... 3'
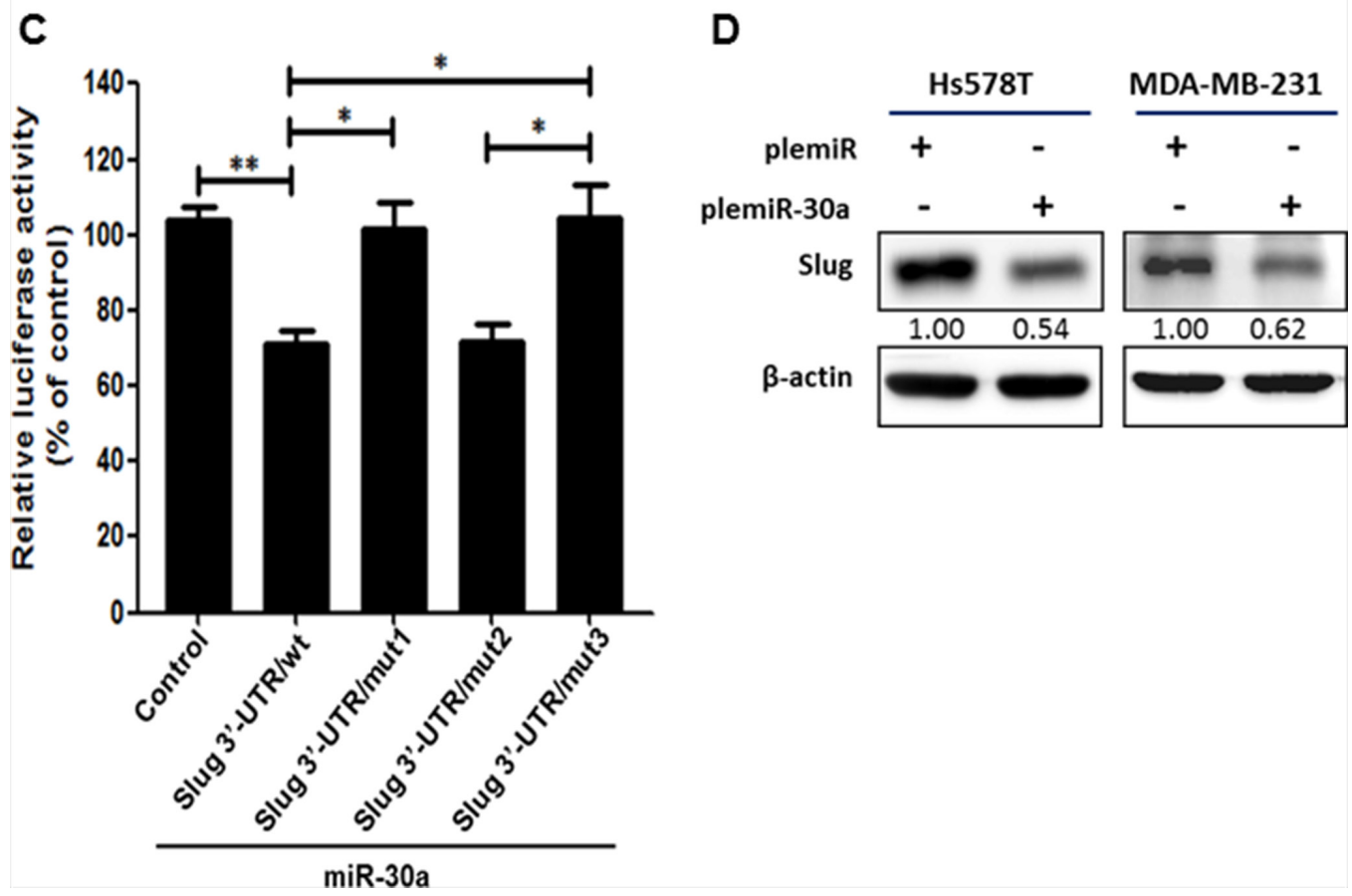

Figure 2: Identification of Slug as a downstream target for miR-30a. (A) Predicted binding sites for miR-30a within the 3'-UTR of Slug mRNA. The 3'-UTR of Slug contains two binding regions for miR-30a (in red) across different vertebrate species. (B) Schematic representation of the luciferase reporter constructs showing the sequences at sites 1 and 2 of the three mutants (shown in red) with a mismatch of the miR-30a complementary sequence at site 1 (Slug 3'-UTR/mut1), site 2 (Slug 3'-UTR/mut2), or both sites (Slug 3'-UTR/ mut3). The wild-type miR-30a-binding sequences are underlined. (C) Luciferase activity was evaluated in Hs578T cells expressing the constructs shown in (B). Firefly luciferase activity was normalized to Renilla luciferase activity and compared with the expression in cells transfected with the pcDNA3 empty vector (control). Data are presented as the mean \pm SD from three independent experiments. $* P<0.05$, $* * P<0.01$. (D) Western blot showing Slug expression in breast cancer cell lines transfected with plemiR-30a. $\beta$-actin was used as the loading control. 


\section{miR-30a represses Slug to increase claudins in conjunction with the MET reversion}

As we demonstrated, miR-30a induction led to a diminution of the elongated and spindle-like fibroblastic phenotype in Hs578T and MDA-MB-231 invasive breast cancer cell lines (Figure 1D), in which E-cadherin is intrinsically deficient (ref. [11] and Figure 1C). We speculated that mesenchymal tumor cells may regain the cobblestone-like epithelial phenotype through activation of other Slug-regulated cellular transmembrane proteins for MET transversion, i.e., those other than E-cadherin. Because (a) claudin-based tight junction proteins are crucial for the barrier function of epithelial cell sheets in mammals [15] and (b) the E-box motif (CANNTG) in the human $C L D N 1$ promoter region (Figure $3 \mathrm{~A}$ ) is bound by Snail family members and Slug overexpression decreases CLDN1 mRNA and protein [16], we thus examined whether the repression of Slug through miR-30a overexpression could increase CLDN-1 expression. Based on chromatin immunoprecipitation (ChIP) with an antibody against Slug, capture of the CLDN1 fragment (Figure 3B) was reduced in MDA-MB-231 cells stably expressing miR-30a as compared with cells containing the plemiR empty vector. In addition, the promoter regions of CLDN2 (nt -803 to -717 ) and CLDN3 (nt -462 to -363 ) share the E-box motifs for Slug binding (Figure 3A), and indeed the ChIP assay showed a similar decrease in the CLDN2- and CLDN3-captured fragments in cells overexpressing miR-30a (Figure 3B). At the protein level, we also found that the levels of CLDN-1, -2 , and -3 were higher in MDA-MB-231 cells transfected with plemiR-30a compared with controls (Figure 3C). In parallel, Slug expression was restored in conjunction with decreased levels of the CLDNs in plemiR-30atransduced MD-MBA-231 cells upon transfection with an inhibitor against miR-30a (anti-miR-30a) compared with expression in the negative control (anti-miR(NC)) (Figure 3C).

Invasive cancer cells typically exhibit increased F-actin polymerization during EMT [17]. We thus examined the effect of miR-30a overexpression on the blockage of F-actin polymerization in invasive breast cancer. Labeling of MDA-MB-231 and Hs578T cells with Alexa Fluor 488-conjugated phalloidin revealed substantial disorganization of microfilaments in cells overexpressing miR-30a (Figure 3D); notably, fewer filopodia per cell were counted in miR-30a-expressing cells compared with expression of the vector alone (Figure 3E). In accordance with this phenotypic change, analysis of fluorescence images also revealed strong staining for claudins along the cell boundaries of both MDA-MB-231 and Hs578T cells stably expressing miR-30a (Figure 3F).

\section{miR-30a represses Slug to inhibit invasiveness of} breast cancer

Overexpression of Slug causes EMT, which leads to tumor aggressiveness by upregulation of the mesenchymal markers vimentin and fascin and downregulation of epithelial markers E-cadherin, occludins, and claudins $[18,19]$. We therefore examined the suppressive function of miR-30a in breast cancer progression in conjunction with characteristic changes in EMT markers. As expected, the number of invading cells was reduced in MD-MBA-231 cells lentivirally transduced with miR-30a by $\sim 40 \%$ compared with control transduced cells (Figure 4A). Slug is required for fascin transcription and translation [18]. Thus, the reduction of Slug and fascin protein levels in the miR-30a-transduced breast cancer cells was abrogated upon transfection with the miR-30a inhibitor (anti-miR-30a), which resulted in enhanced tumor cell invasion as compared with control oligonucleotide-transfected cells (Figure 4A-4B). In parallel, knockdown of Slug expression in MDA-MB-231 cells increased claudin expression to inhibit cancer cell invasion (Figure 4B). Notably, this inhibition of invasion by sh-Slug treatment did not change in the presence of miR-30a overexpression (or miR control) (Figure 4C), and no changes in fascin or claudin expression were seen in sh-Slug cells overexpressing miR-30a (miR-30a-mimic) (Figure 4D). This suggests that miR-30a cannot inhibit cancer cell invasion in the absence of Slug.

\section{miR-30a overexpression inhibits lung colonization and tumor growth in xenograft transplantation models of human breast cancer}

Given these findings in vitro, we next evaluated the in vivo effects of miR-30a on orthotopic tumor metastasis and outgrowth with an experiment in nude mice. We established a xenograft model of human breast cancer metastasis by injection of MDA-MB-231 cells transfected with empty vector (control) or the miR-30a overexpression vector into the tail vein of 6-week-old mice. After 5 weeks, mice were sacrificed and their lungs dissected to evaluate tissue morphology by hematoxylin and eosin (HE) staining (Figure 5A). Tumors with high expression of miR-30a formed only a few pulmonary metastatic nodules on average $(16.0 \pm 10.8)$ in all mice analyzed and significantly fewer than the number of nodules formed in the control group $(139.2 \pm 35.2, P=0.0028)$ (Figure 5B). We also injected breast tumor cells into the mammary fat pads of mice to study the effect of miR-30a on inhibition of tumor outgrowth. After 4 weeks, the subsequent tumors in the mice injected with MDA-MB-231 cells that overexpressed miR-30a were significantly 
A

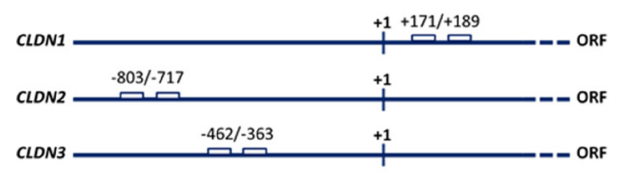

B

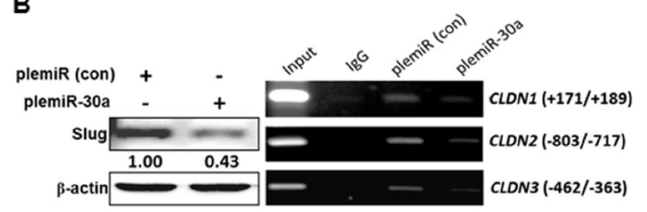

C
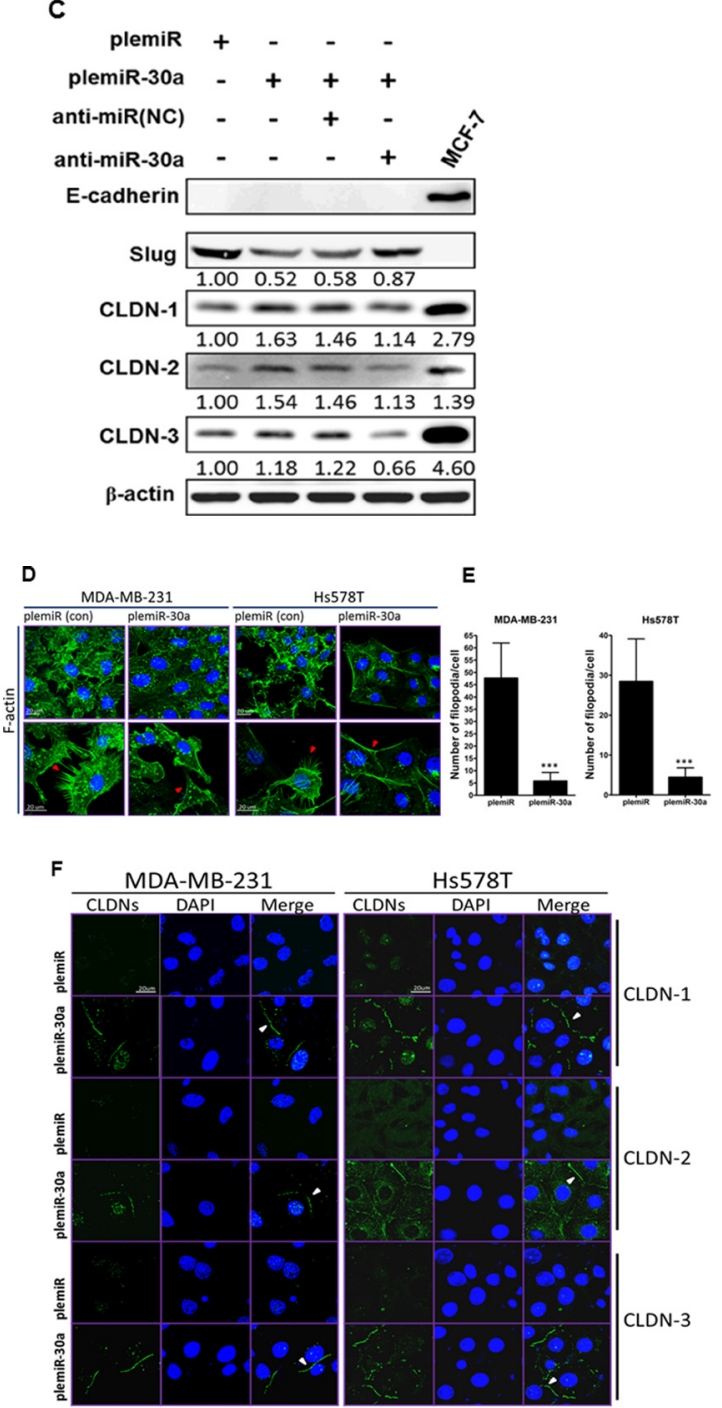

Figure 3: Claudin expression is enhanced by the miR-30a/Slug axis. (A) Schematic of the E-boxes in the promoter regions of human $C L D N 1, C L D N 2$, and $C L D N 3$. The starting point (+1) indicates the transcription initiation in the open reading frame (ORF) of the gene. (B) Western blotting (anti-Slug) of MDA-MB-231 breast cancer cell lysates after lentiviral transduction of miR-30a (left panel). PCR analysis of the genes encoding CLDN-1,-2, and -3 after ChIP in the presence of anti-Slug or anti-IgG from control MDA-MB-231/plemiR cells (con) and MDA-MB-231/plemiR-30a cells (right panel). (C) Western blotting revealed that Slug and fascin expression in miR-30aoverexpressing cells following miR-30a knockdown (anti-miR-30a) was inversely correlated with claudin expression. NC, negative control. (D) Microfilaments in MDA-MB-231 and Hs578T cells expressing plemiR-30a or the control construct plemiR were detected with Alexa Fluor 488-conjugated phalloidin (green) as indicated by red arrows. (E) The number of filopodial tips per cell as averaged from 50 cells per condition was calculated. The data represent the mean $\pm \mathrm{SD}$ from three independent experiments. $* * * P<0.001$. (F) Expression of CLDN-1, -2 , or -3 (green) was distributed around the cell boundary (white arrowheads) in breast cancer cell clones stably expressing miR-30a, but not in those expressing plemiR. Nuclei were counterstained in (D) and (F) with DAPI (blue). Scale bar $=20 \mu \mathrm{m}$. 
smaller than those in the control group $(P<0.001)$ (Figure 5C-5D). Breast tumor tissues from mice were resected and then subjected to immunohistochemical staining. The resultant positive staining for CLDN-1, -2 , and -3 that was associated with decreased expression of Slug and fascin differentiated the orthotopic tumor tissues with miR-30a overexpression from those carrying vector alone (Figure 5E). This supported a suppressive function for miR-30 in breast cancer invasiveness and metastasis in vivo.

\section{The miR-30a ${ }^{\text {low }} / C L D N^{\text {low }} / F S C N^{\text {high }}$ genotype in association with breast cancer progression}

Our results at the molecular and cellular levels were thus consistent with those from an animal model, all of which indicated that increased expression of CLDN1, CLDN-2, and CLDN-3 and decreased expression of fascin are controlled by the miR-30a/Slug axis. We therefore determined whether there is an association between miR-30a/claudin/fascin and clinicopathological
A

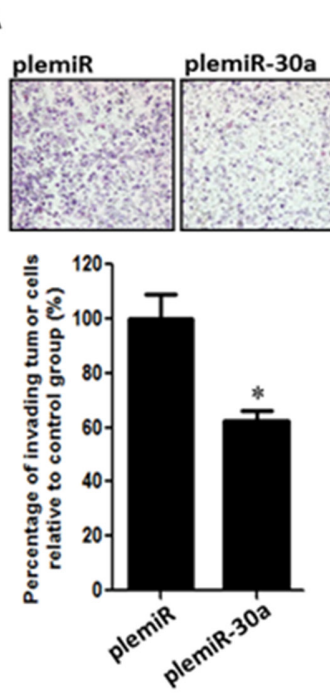

plemiR-30a/ plemiR-30a/

anti-miR (NC) anti-miR-30a sh-luc

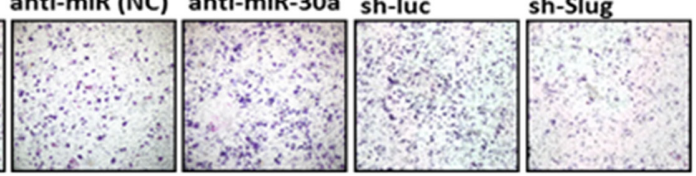

C
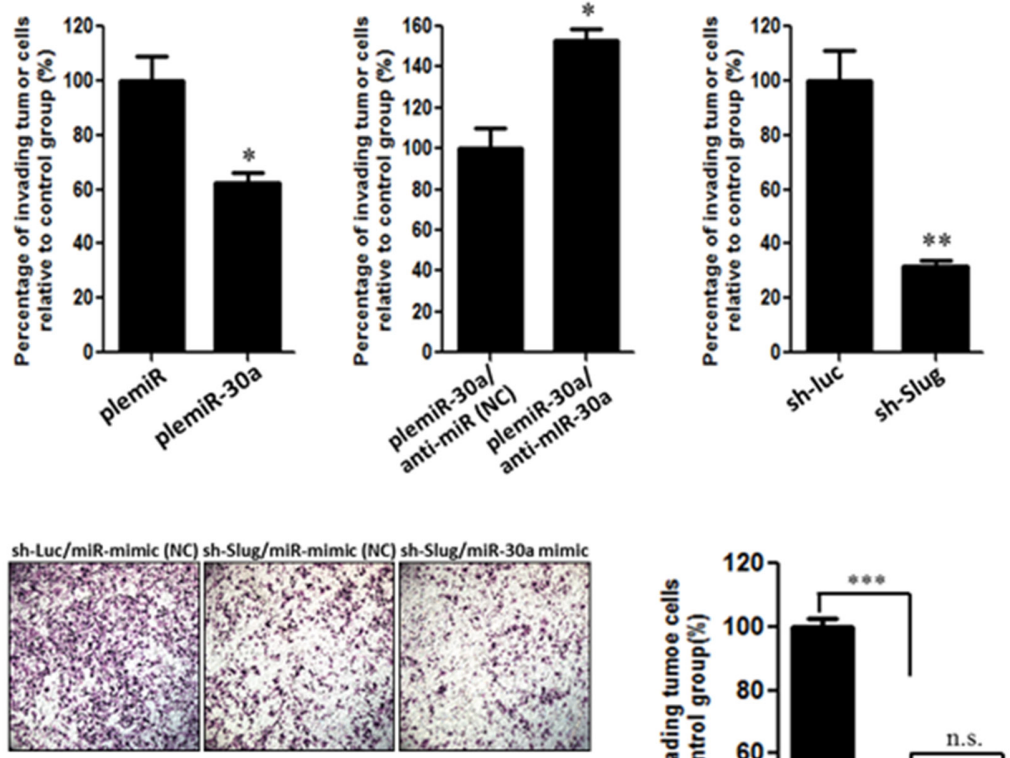
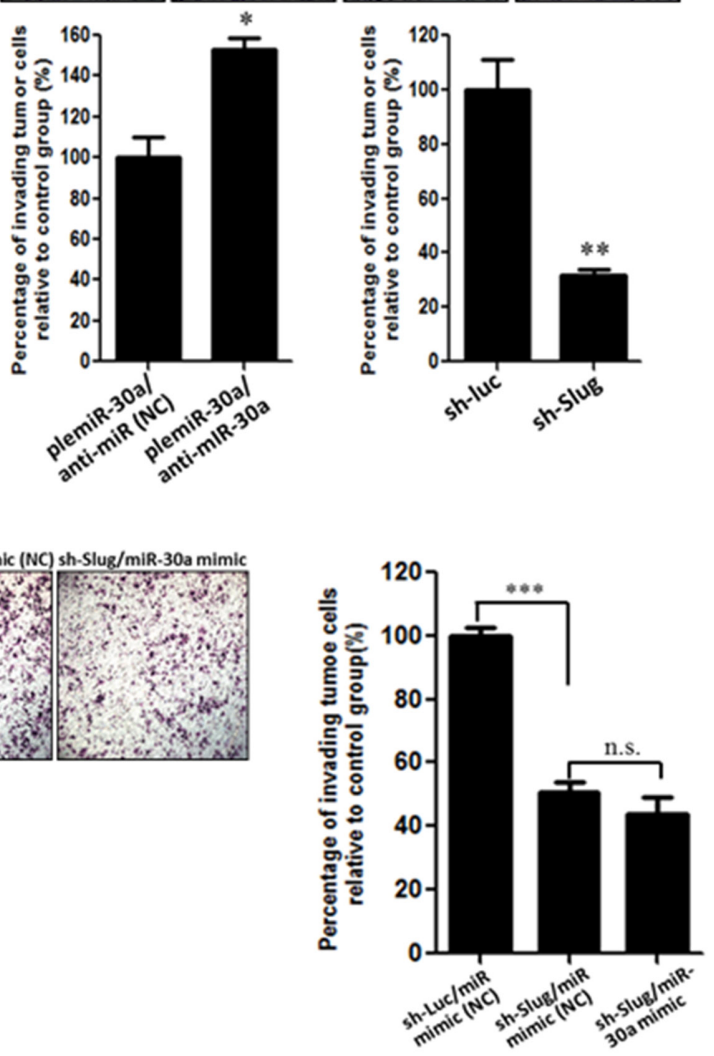

B
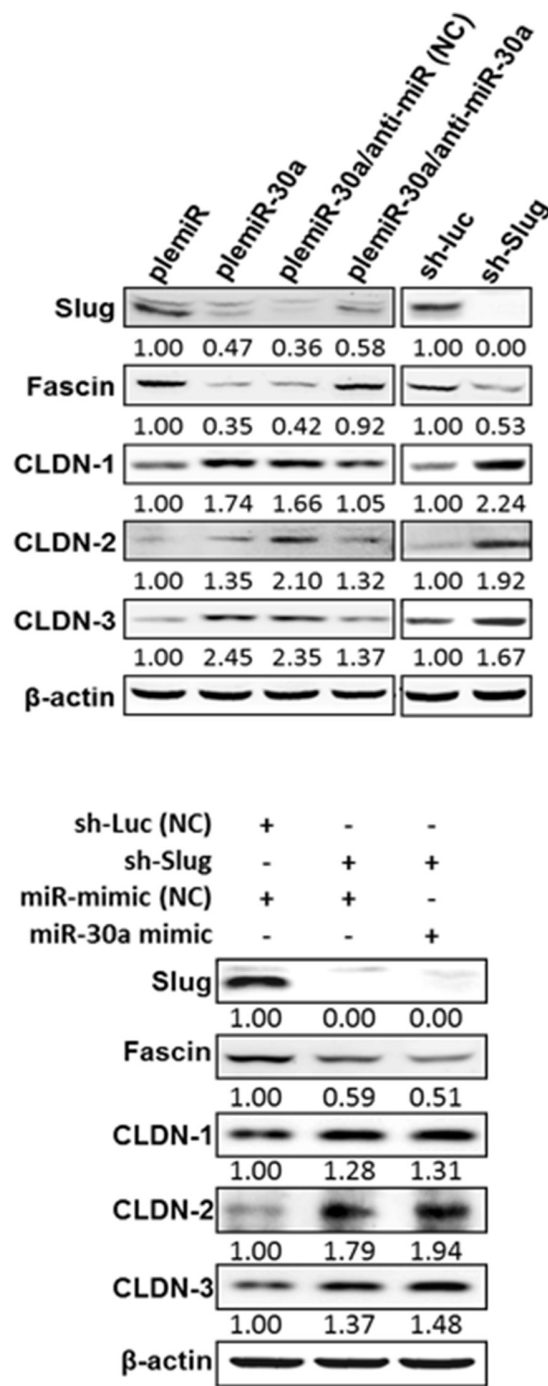

Figure 4: miR-30a decreases the invasiveness of breast cancer cells. (A) MDA-MB-231 cells were transfected with plemiR or plemiR-30 and then treated with miR-30a inhibitor (anti-miR-30a) or underwent Slug knockdown with a Slug-specific short hairpin RNA (sh-Slug) or sh-Luc, a control shRNA. The cells were plated in modified Boyden chambers with polycarbonate membranes containing Matrigel and cultured for $12 \mathrm{~h}$. Cells were then fixed, stained with Giemsa solution, and photographed ( $\times 200)$. Upper panel: Cells that invaded through the pores onto the lower side of the filter. Lower panel: The invading cells were counted in eight randomly chosen microscope fields. Data are shown as the mean \pm SD from three independent experiments. $* P<0.05, * * P<0.01$. (B) Reduced Slug and fascin expression, but increased claudin levels, as determined by western blot analysis, in MDA-MB-231 cells expressing plemiR-30a or shRNA-Slug, as compared with controls plemiR or shRNA-Luc, respectively. In addition, Slug and fascin protein levels were restored in plemiR-30a-expressing/MDA-MB-231 cells transfected with anti-miR-30a. $\beta$-actin was the loading control. (C) Knockdown of Slug notably decreases the invasion of MDA-MB-231 cells, whereas overexpression of miR-30a fails to abrogate the reduced frequency of invasion for sh-Slug/MDA-MB-231 cells. (D) The expression of Slug, fascin, and claudins was also analyzed by western blotting. $\beta$-actin was the loading control. 
A

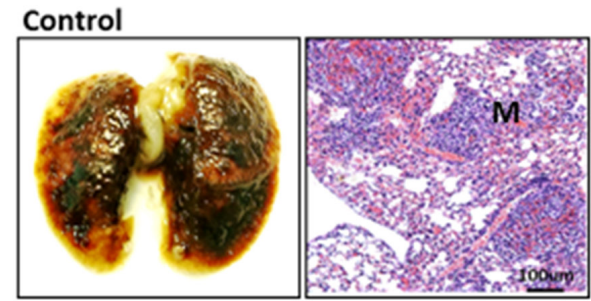

miR-30a

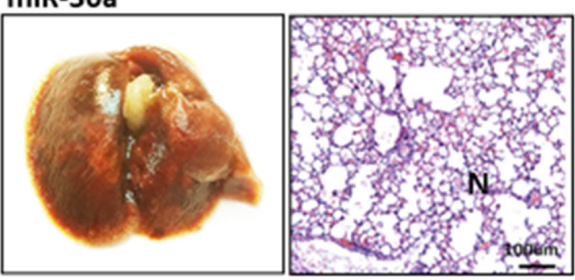

C

MDA-MB-231/plemiR

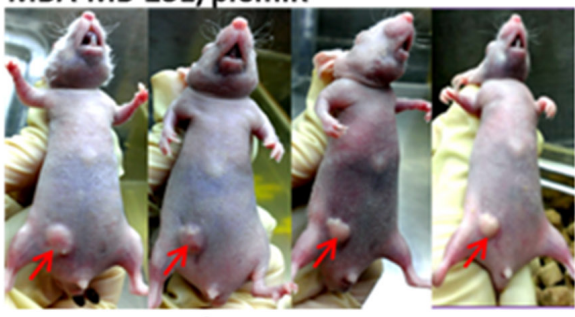

MDA-MB-231/plemiR-30a

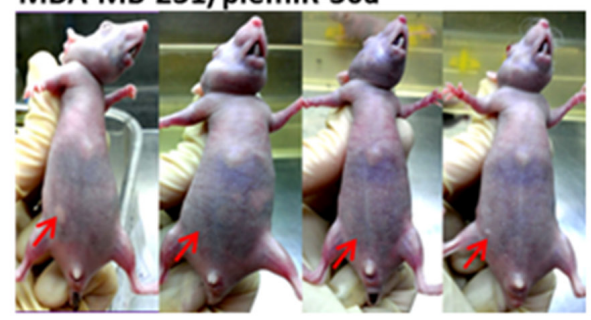

B

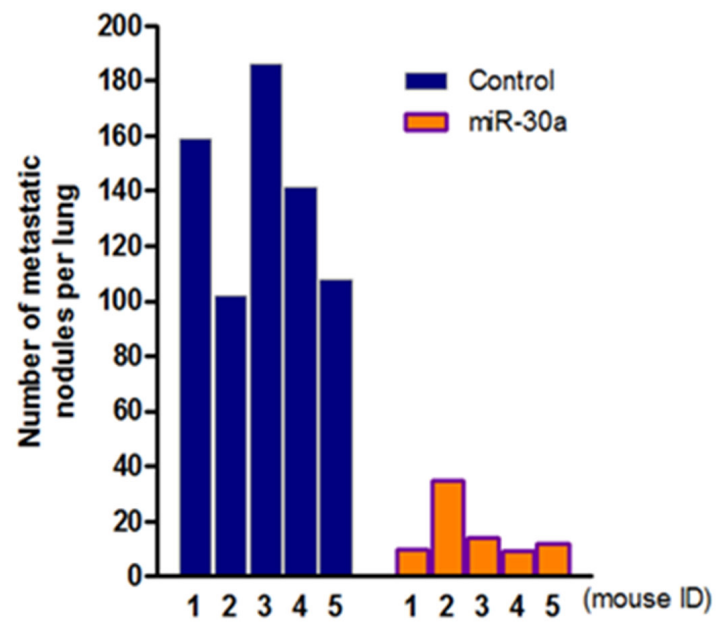

D

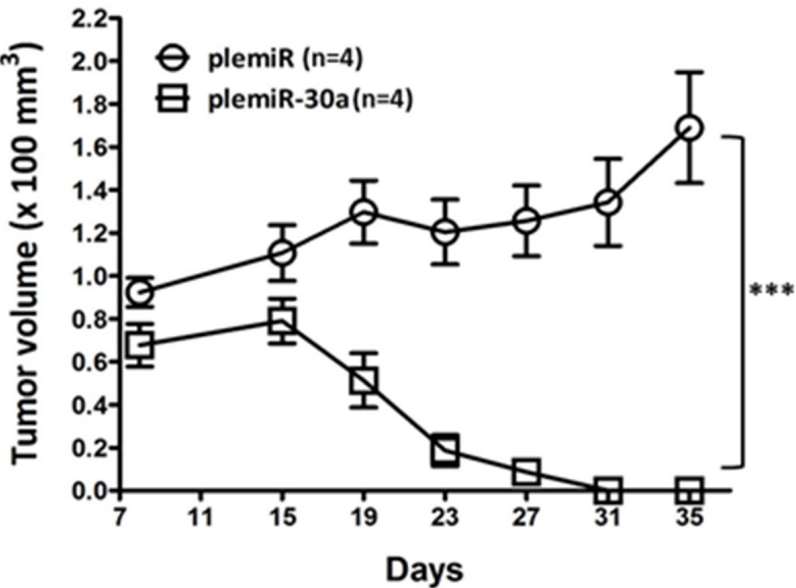

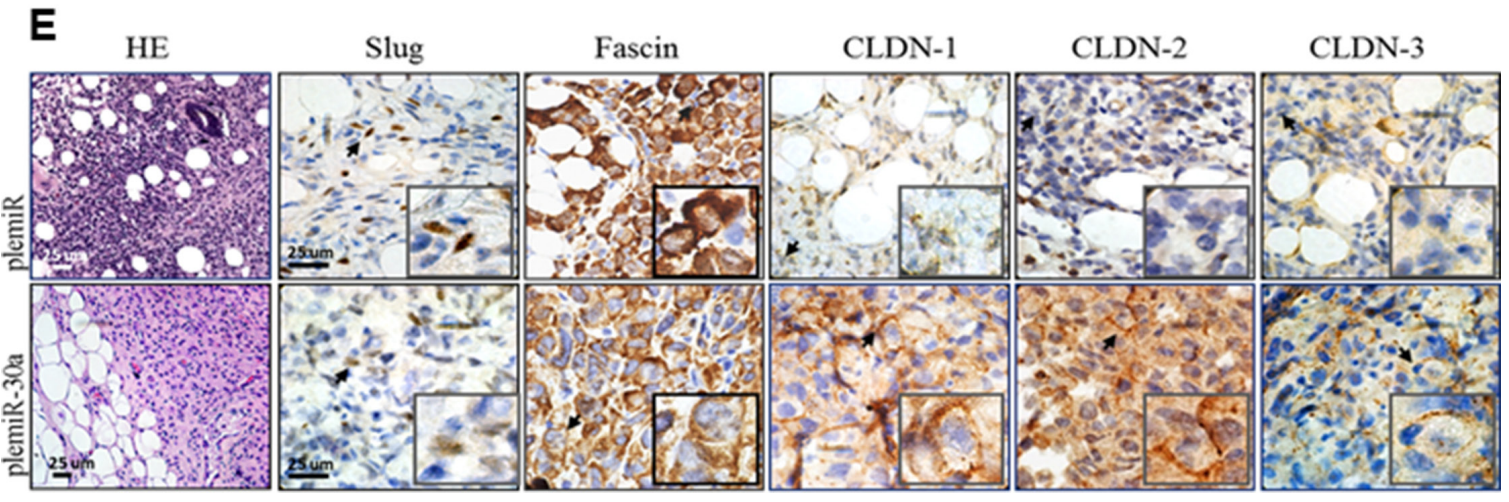

Figure 5: Ectopic expression of miR-30a inhibits tumor growth and metastatic lung colonization of breast cancer xenografts. (A) Representative lungs and HE staining of metastatic tumor (M) and normal (N) lung tissues from mice 5 weeks after tail vein injection of MDA-MB-231 cells overexpressing miR-30a or plemiR vector (control). (B) Number of metastatic nodules in lungs of mice ( $n=5$ per group) as in (A). (C) Reduced tumor volumes in fat pads of nude mice injected with MDA-MB-231 cells stably overexpressing miR-30a or the control plemiR. The red arrows indicate tumors. (D) Xenograft tumor volumes from mice as in (C). Data represent the mean $\pm \mathrm{SD}$. ${ }^{* * *} P<0.001$. (E) Photographs of representative mice at 5 weeks post-xenotransplantation. Tumors were excised and sectioned and are shown with HE staining and specific staining for expression of Slug, fascin, and claudins (CLDN-1,-2, and-3). Scale bar $=25 \mu \mathrm{m}$. 
Table 1: Tumor clinicopathological features of female patients with breast cancer

\begin{tabular}{|c|c|}
\hline \multicolumn{1}{|c|}{ Clinicopathological feature } & $50.3 \pm 12.6(23-87 \mathrm{yr})$ \\
\hline Age (mean \pm SD and range) & $42(48.8)$ \\
\hline Tumor size $(\mathrm{mm})$ & $44(51.2)$ \\
\hline$\leq 20$ & \\
\hline$>20$ & $13(15.1)$ \\
\hline Histologic grade & $40(46.5)$ \\
\hline I & $33(38.4)$ \\
\hline II & $27(31.4)$ \\
\hline III & $27(31.4)$ \\
\hline AJCC stage ${ }^{\mathrm{a}}$ & $14(16.3)$ \\
\hline I & $15(17.4)$ \\
\hline IIa & $3(3.5)$ \\
\hline IIb & \\
\hline III & $41(47.7)$ \\
\hline IV & $45(52.3)$ \\
\hline Lumor extension in metastatic lymph node & \\
\hline LNM-negative (N $)^{\mathrm{b}}$ & \\
\hline LNM-positive (N/N $/{ }_{2}$ & \\
\hline
\end{tabular}

${ }^{a}$ Tumor classification was based on the sixth edition of the AJCC Cancer Staging Manual [40]. ${ }^{b}$ LNM, lymph node metastasis.

significance of breast cancer. We used laser capture microdissection to isolate tumor cells from specimens to avoid contamination with normal tissue and then measured the expression of individual genes by quantitative realtime PCR. In our breast cancer cohort $(n=86)$ (Table 1), CLDN2 mRNA transcripts were significantly and positively associated with miR-30a levels in cancerous tissues (Pearson correlation coefficient, $0.375 ; P=0.0004$ ) (Figure 6A). In contrast, FSCN mRNA had an opposite correlation with miR-30a (Pearson correlation coefficient, -0.424; $P<0.0001$ ) (Figure 6B). In addition, a high level of $C L D N 2$ mRNA was correlated with a low level of FSCN mRNA (Pearson correlation coefficient, -0.324 ; $P=0.0023$ ) (Figure 6C).

To assess the prognostic prediction of the interaction between miR-30a and FSCN or between miR-30a and $C L D N 2$ in breast cancer, we defined expression status as "high" ( $\geq 4.90$-fold increase in FSCN mRNA compared with the median) or "low" ( $<2.40$-fold decrease in $C L D N 2$ mRNA) by comparing expression in cancer cells and adjacent non-cancerous cells. With miR-30 $\mathrm{a}^{\text {high/ }}$ $F S C N^{\text {low }}$ and $\mathrm{miR}-30 \mathrm{a}^{\text {high }} / C L D N 2^{\text {high }}$ as the reference, there was a greater proportion of the miR-30a $\mathrm{a}^{\text {low }} / F S C N^{\text {high }}$ and $\mathrm{miR}-30 \mathrm{a}^{\text {low }} / C L D N 2^{\text {low }}$ genotype, respectively, in cancer patients with a large tumor size, advanced tumor stage, or lymph node involvement $(P$ for trend $<0.05)$ at the time of diagnosis (Table 2).

We next addressed the question regarding joint effects of miR-30 ${ }^{\text {low }} / C L D N 2^{\text {low }} / F S C N^{\text {high }}$ on prognostic assessment of breast cancer. A joint effect of higher risk associated with poor clinicopathological features of breast cancer was observed in patients who more closely adhered to the miR-30a $a^{\text {low }} / C L D N 2^{\text {low }} / F S C N^{\text {high }}$ genotype (Table 3). We analyzed the statistical significance with the trend test for one additional risk genotype in individuals with a large tumor size, lymph node metastasis, or advanced tumor stage as measured by the $\beta$ estimates from the regression model $(P$ for trend $<0.05$ ) (Table 3 ).

More specifically, the differences in the expression of the proteins encoded by these genes were validated by immunohistochemistry in breast cancer tissue specimens, and the results were stratified based on the miR-30a level (Figure 7A). In the immunohistochemical analysis $(n=10)$, tissues that expressed high levels of miR-30a (tumor-to-normal $(\mathrm{T} / \mathrm{N})$ ratio $\geq 0.50$-fold as defined in [10]), had intense positive staining for the three claudin proteins, and had reduced or undetectable levels of Slug and fascin were from well-differentiated, lymph node 


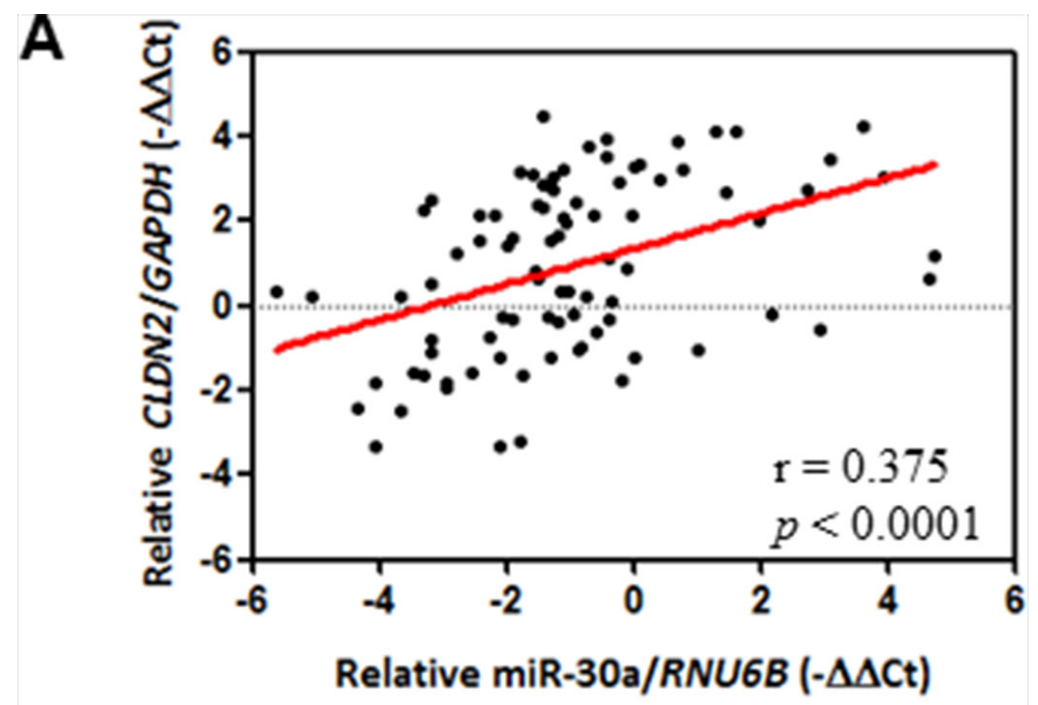

B
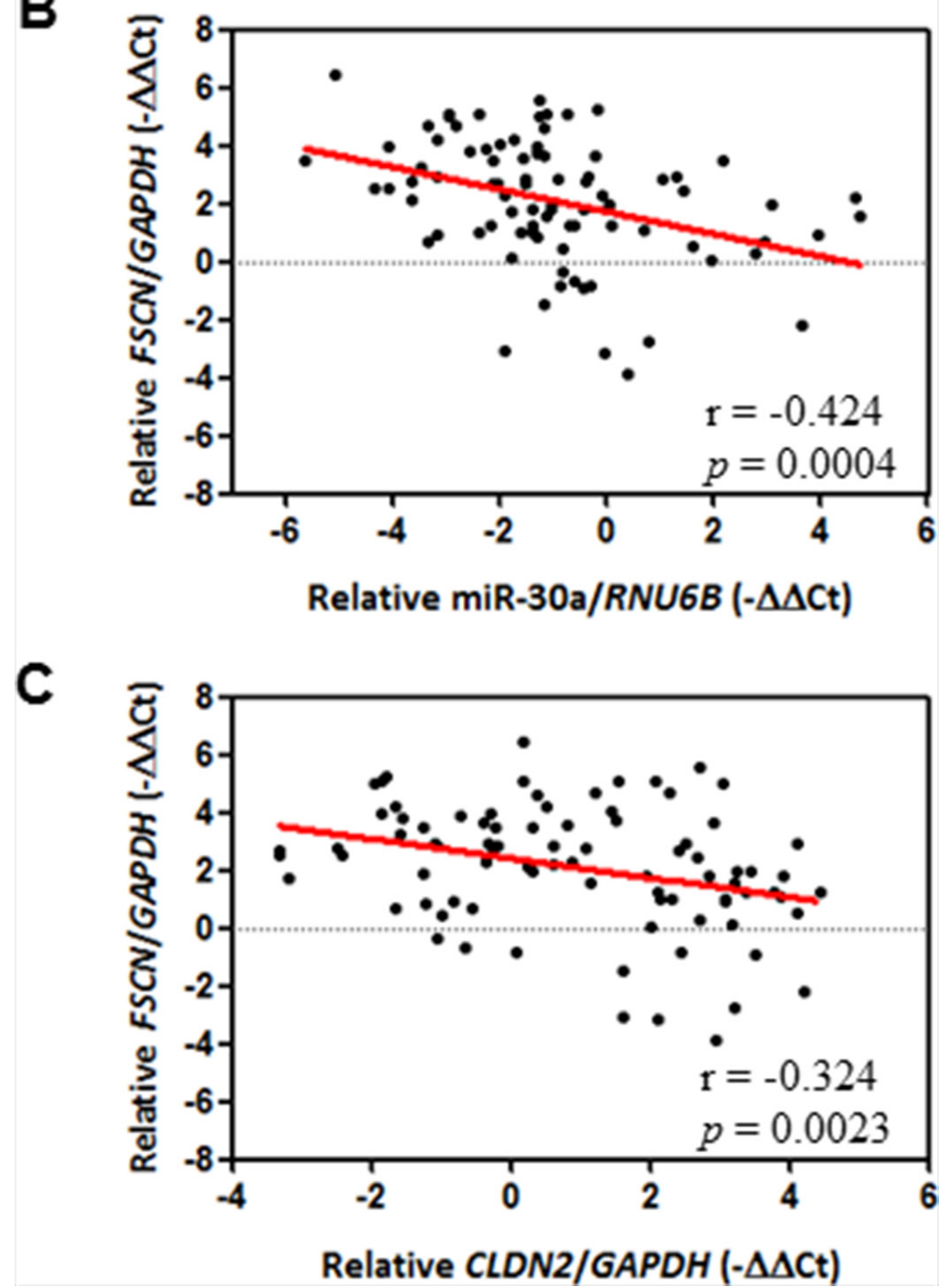

Figure 6: Correlation between miR-30a and EMT markers. The Pearson correlation coefficient was used to analyze mRNA expression data from 86 patients with breast cancer. (A) Positive correlation between miR-30a and epithelial marker CLDN2. (B) Inverse correlation between miR-30a and mesenchymal marker FSCN (C) Inverse correlation between CLDN2 and FSCN. The relative expression of each mRNA was calculated using the comparative CT method. 


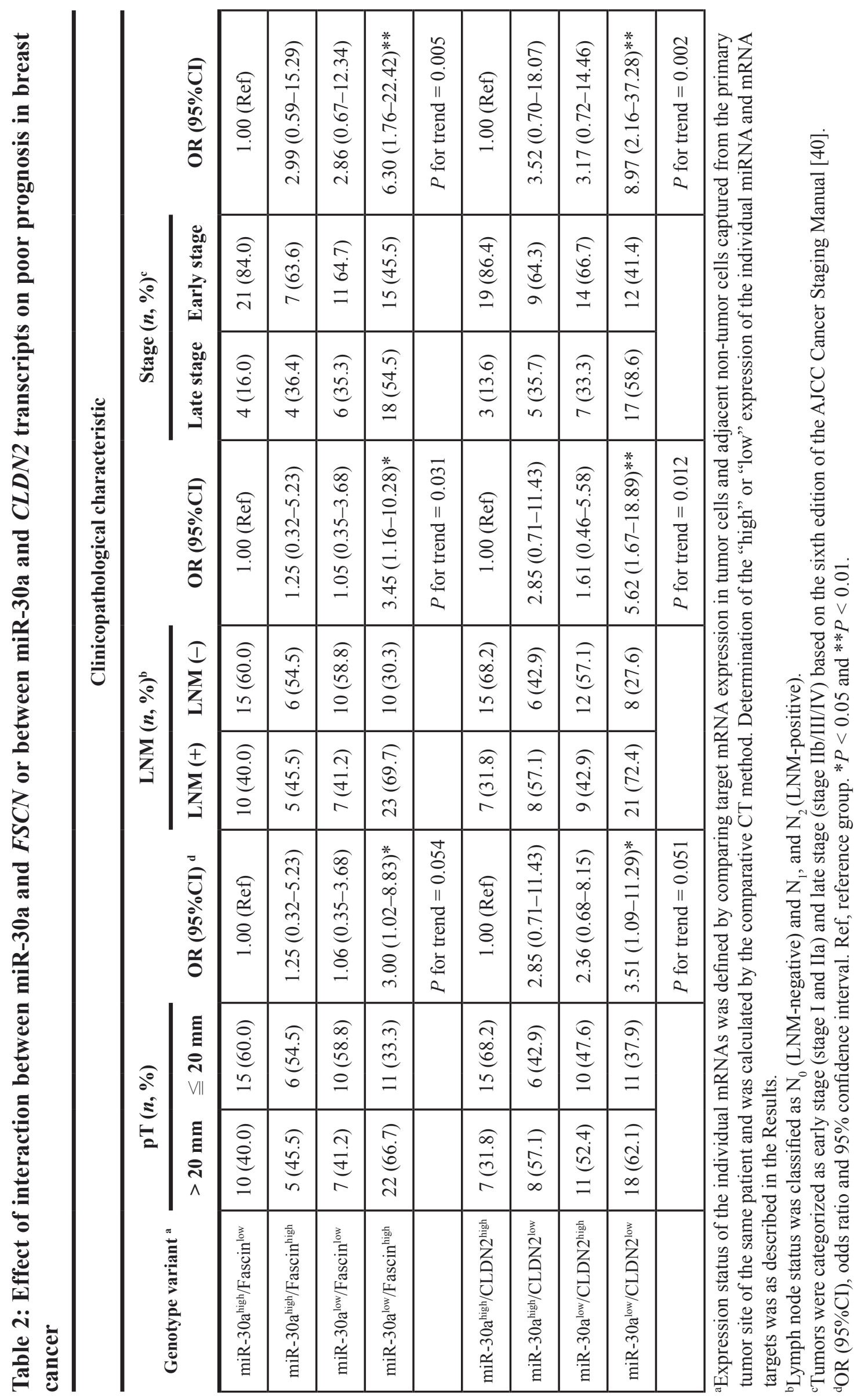


Table 3: Additive effect of the tumors with greater numbers of deregulated mRNAs (miR-30a, $C L D N 2$, and $F S C N$ ) on clinicopathological characteristics in breast cancer

\begin{tabular}{|c|c|c|c|c|c|c|}
\hline \multirow{3}{*}{$\begin{array}{c}\text { Number of } \\
\text { deregulated } \\
\text { mRNAs relative } \\
\text { to } \mathrm{miR}^{-30 a^{\text {low }} /} \\
\text { CLDN } 2^{\text {low }} / F S C N^{\text {high a }}\end{array}$} & \multicolumn{6}{|c|}{ Clinicopathological characteristic } \\
\hline & \multicolumn{2}{|c|}{ pT $(>20 \mathrm{~mm})$} & \multicolumn{2}{|c|}{ LNM-positive } & \multicolumn{2}{|c|}{ Tumor stage (III/IV) } \\
\hline & $n(\%)$ & OR $(95 \% \mathrm{CI})^{\mathrm{b}}$ & $n(\%)$ & OR $(95 \% \mathrm{CI})$ & $n(\%)$ & OR $(95 \% \mathrm{CI})$ \\
\hline 0 & $7(38.9)$ & 1.00 (Ref) & $6(33.3)$ & 1.00 (Ref) & $3(16.7)$ & 1.00 (Ref) \\
\hline 1 & $8(36.4)$ & $0.90(0.25-3.24)$ & $8(36.4)$ & $1.14(0.31-4.23)$ & $4(18.2)$ & $1.12(0.21-5.76)$ \\
\hline 2 & $13(56.5)$ & $2.04(0.58-7.17)$ & $14(60.9)$ & $3.11(0.86-11.29)$ & $11(47.8)$ & $4.58(1.04-20.24)^{*}$ \\
\hline 3 & $16(69.6)$ & $3.59(0.98-13.16)$ & $17(73.9)$ & $5.67(1.47-21.89)^{*}$ & $14(60.9)$ & $7.78(1.74-34.72)^{* *}$ \\
\hline $\begin{array}{c}\text { Additive model of } \\
\text { deregulated miRNAs }\end{array}$ & & $\begin{array}{c}1.62(1.08-2.43) \\
P \text { for trend }=0.021\end{array}$ & & $\begin{array}{c}1.89(1.23-2.89) \\
P \text { for trend }=0.003\end{array}$ & & $\begin{array}{c}2.21(1.38-3.54) \\
P \text { for trend }=0.001\end{array}$ \\
\hline
\end{tabular}

${ }^{\text {a }}$ Cutoffs of miR-30a ${ }^{\text {low }}, C L D N 2^{\text {low }}$, and $F S C N^{\text {high }}$ genotypes were as described in the Results.

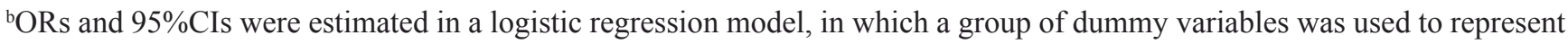
different groups of patients showing different numbers of risk genotypes. $* P<0.05 ; * *<0.01$.

metastasis (LNM)-negative, and non-invasive tumors. In contrast, the advanced breast tumor tissues (late stage and LNM-positive) with decreased ( $\mathrm{T} / \mathrm{N}$ ratio $<0.50$-fold) or undetecTable miR-30a (T/N ratio $<0.10$-fold) had lowintensity staining for claudins but strong intensity for Slug and fascin (Supplementary Table S1).

\section{DISCUSSION}

miR-30a inhibits EMT in different types of cancer, including gastric, liver, and lung cancer [12, 20, 21]. Here we propose a mechanism for this effect by which miR-30a counteracts the aggressiveness and metastasis of cancer cells by increasing tight junction molecules - CLDN-1, CLDN-2, and CLDN-3 - via targeting the 3'-UTR of Slug mRNA. This increased expression of claudins can support tight junction function, which may regulate EMT and eventually prevent breast cancer progression (Figure 7B). Together, these findings may help to develop a candidate miRNA biomarker that could lead to prognostic assessment for breast cancer patients.

The in silico prediction, luciferase reporter assay, and western blotting all indicated that Slug mRNA is a direct target of miR-30a. According to data sorting of the mRNA sequences bound to miRNAs, miR-30 family members (miR-30a, -30b, -30c, -30d, and -30e) share the same seed sequence (Supplementary Figure S1), suggesting that other miR-30 family members may also suppress Snail or Slug. Indeed, decreased luciferase activity in a reporter assay showed that the 3 '-UTR of Snail mRNA is a direct target of miR-30a in breast cancer cells (Supplementary Figure S2), and this is consistent with a previous report that miR-30a overexpression downregulates Snail and thereby inhibits invasion and metastasis of lung carcinomas [12]. Likewise, miR$30 \mathrm{c}$ is significantly downregulated in human renal cell carcinomas, in which miR-30c overexpression may suppress EMT by binding Slug mRNA to increase E-cadherin production [22]. Additional studies are needed to determine whether defects in miR-30 family members act independently or jointly to drive the progression of breast cancer.

Slug can promote the formation of filopodialike bundles via transcriptional activation of FSCN $[18,23]$ to sustain filopodial tips during the metastasis and invasion of cancer cells [24, 25]. The miR-30a/ Slug axis inhibited filopodial assembly during EMT in breast cancer cells, which resulted in reduced levels of mesenchymal proteins, e.g., vimentin and fascin. miR-30 family members, including miR-30a, are downregulated in estrogen receptor-negative and progesterone receptornegative breast tumors, suggesting that these hormones are involved in de novo synthesis of miR-30 family members $[26,27]$. We are currently mapping the specific region that harbors the hormone-response element(s) in the miR-30 promoter and will identify the hormonal mechanism that regulates miR-30 expression, which could help determine the clinical benefit of endocrine therapy in individuals with hormone receptor-positive breast cancer. 
Additional miR-30a-regulated targets have been identified and their functions defined, including involvement in tumor cell autophagy [28], mediating cisplatinum chemosensitivity [29], suppressing metastatic colorectal cancer by inactivating the Akt/mTOR pathway [30], and inhibiting breast cancer metastasis by decreasing metadherin [31]. Our present miRNA study demonstrates that Slug, as well as vimentin [10], is a miR-30a target that is particularly important in breast cancer progression. In addition, clinical observations, including those of our breast cancer cohort [10,31], showed that miR-30a reduction is associated with lymph node and lung metastases in patients with breast cancer. Importantly, miR-30a inhibits the attachment-independent growth of breast tumor-initiating cells identified in a subset of tumors with unlimited self-renewal and differentiation heterogeneity [32]. The exclusively tumor-suppressive effect of miR-30a in the regulation of multiple important tumorigenic genes/pathways involved in cancer cell heterogeneity may drive the development and evaluation of miR-30a as a therapeutic for breast cancer.

\section{CONCLUSION}

The tumor-suppressive function of miR-30a reverses EMT in breast cancer by directly targeting the 3'-UTR of Slug. In vitro binding of miR-30a to Slug mRNA increased expression of the tightjunction proteins CLDN-1, -2 , and -3 and decreased the metastatic capability of those cells owing to its effects on the reduction of F-actin polymerization. Consequently, tumor progression was suppressed in mouse xenotransplantation assays. Clinically, RNA expression profiles and immunohistochemical analyses confirmed that the miR-30 $\mathrm{a}^{\text {low }} /$ Claudin ${ }^{\text {low }} /$ Fascin ${ }^{\text {high }}$ link correlated with poor prognosis for breast cancer. Thus, miR-30a may be useful as a therapeutic strategy for breast cancer treatment.
A

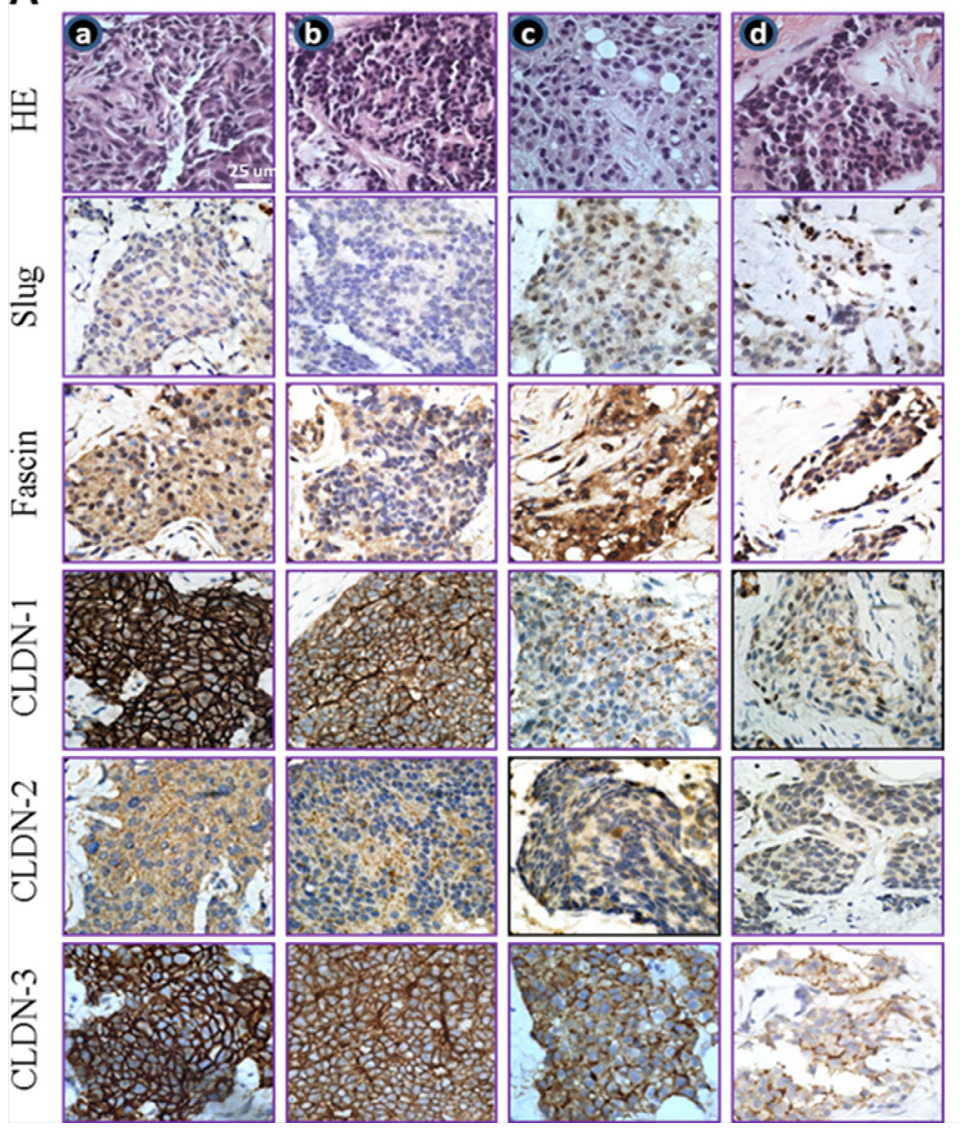

B

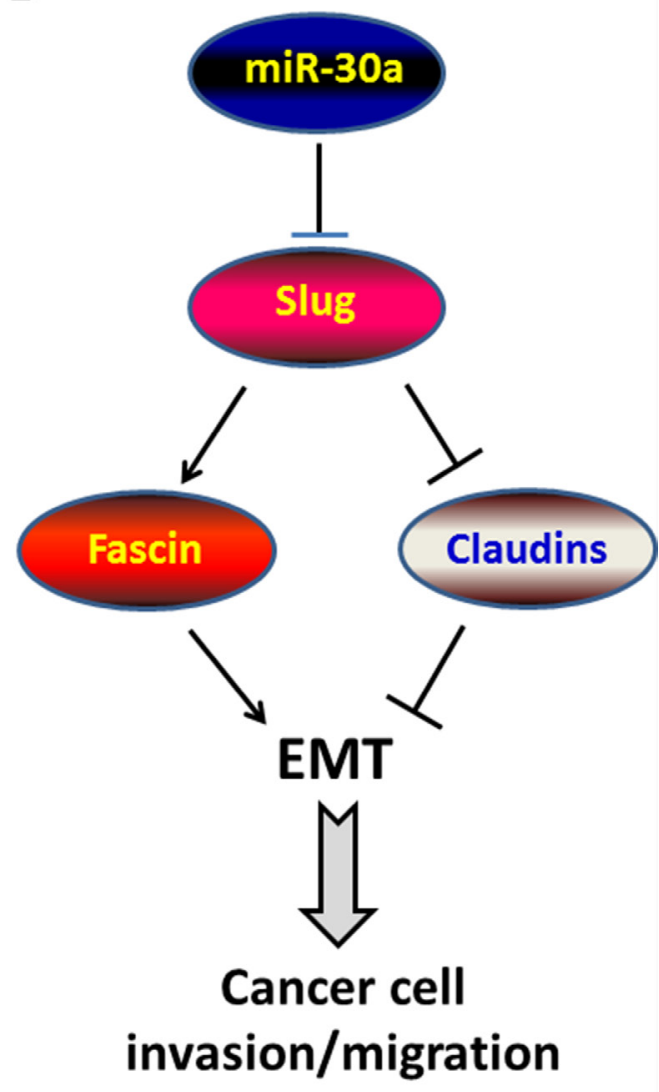

Figure 7: miR-30a inhibits EMT by binding to Slug. (A) The cellular phenotype of miR-30a $\mathrm{a}^{\text {low }} / \mathrm{Slug}^{\text {high }} / \mathrm{Fascin}^{\text {high }} / \mathrm{Claudin}{ }^{\text {low }}$ correlates with poor clinicopathological features in breast cancer. Immunostaining results for paraffin-embedded breast cancer tissue samples of LNM-negative and early-stage tumors (stage I and IIa; columns a and b) and LNM-positive and advanced-stage tumors (stages III and IV; columns $\mathrm{c}$ and d). In addition, the $\mathrm{T} / \mathrm{N}$ ratio for miR-30a was $<0.50$ in columns $\mathrm{c}$ and $\mathrm{d}$ and was $\geq 0.50$ in columns a and $\mathrm{b}$. Clinicopathological features of the tumors were determined according to the sixth edition of the AJCC Cancer Staging Manual [40]. (B) The tumor-suppressor role of miR-30a relative to its inhibition of EMT. The targeting of Slug mRNA by miR-30 results in downregulation of fascin and upregulation of the tight junction proteins CLDN-1, CLDN-2, and CLDN-3, which downregulates EMT and, ultimately, reduces the rate of breast cancer progression. 


\section{MATERIALS AND METHODS}

\section{Cell culture}

The human mammary epithelial cell line, MCF10A, was a kind gift of Dr. Yung-Luen Yu at the Graduate Institute of Cancer Biology, China Medical University, Taichung, Taiwan. MCF-10A cells were maintained in DMEM/F12 medium (Life Technologies, Carlsbad, CA, USA) containing $0.1 \mathrm{mM}$ sodium pyruvate, $5 \%$ horse serum, $10 \mu \mathrm{g} / \mathrm{mL}$ insulin, $2 \mathrm{mM}$ L-glutamine, $100 \mathrm{IU} / \mathrm{mL}$ penicillin, $100 \mu \mathrm{g} / \mathrm{mL}$ streptomycin, $20 \mathrm{ng} / \mathrm{mL}$ epidermal growth factor, $500 \mathrm{ng} / \mathrm{mL}$ hydrocortisone, and $100 \mathrm{ng} / \mathrm{mL}$ cholera toxin in a humidified $5 \% \mathrm{CO}_{2}$ atmosphere at $37^{\circ} \mathrm{C}$. The breast cancer cell lines (Hs578T, MDA-MB-231, MCF-7, and BT-474) and the non-malignant mammary epithelial cell line H184B5F5/M10 were obtained from the American Type Culture Collection (Manassas, VA, USA) and cultured in DMEM (Life Technologies) containing $0.1 \mathrm{mM}$ sodium pyruvate, $10 \% \mathrm{FBS}, 2 \mathrm{mM}$ L-glutamine, $100 \mathrm{IU} / \mathrm{mL}$ penicillin, and $100 \mu \mathrm{g} / \mathrm{mL}$ streptomycin.

\section{Cell lysis and western blotting}

A detailed procedure for western blotting is described elsewhere [10]. Primary antibodies against human Slug and vimentin (Cell Signaling Technology, Danvers, MA, USA); CLDN-1, -2 , and -3 (Novus Biologicals, Littleton, CO, USA); and E-cadherin, $\mathrm{N}$-cadherin, and fascin (Santa Cruz Biotechnology, Dallas, TX, USA) were used. The antibody against $\beta$-actin, which was used as the endogenous control to normalize the expression of proteins of interest, was obtained from Sigma-Aldrich (St. Louis, MO, USA). An appropriate horseradish peroxidase-conjugated secondary antibody was used, and the immunoreactive protein was visualized with an enhanced chemiluminescence assay (Western Blotting Luminol Reagent; Santa Cruz Biotechnology). The band intensities were quantified by densitometry (Digital Protein DNA Imagineware, Huntington Station, NY, USA).

\section{Wound healing assay}

To determine the migratory behavior of MCF-7 cells, a bidirectional wound healing assay was performed [33]. Briefly, cells were grown in medium to monolayer confluence in 24-well culture plates. Cells were treated with anti-miR-30a or anti-miR-mimic (NC), and after which a sterile $10-\mu \mathrm{L}$ tip was used to scratch the monolayer of cells to form a bi-directional wound. The plate was kept in a $37^{\circ} \mathrm{C}, 5 \% \mathrm{CO}_{2}$ incubator overnight. Pictures of a representative field of the cell-free space were taken at 0 and $24 \mathrm{hr}$ after the scratch using a microscope, and the distance of cell migration was calculated with Image Pro plus software (Media Cybernetics, Silver Spring, USA).

\section{Dual luciferase reporter assay}

The 3'-UTR sequence of human Slug was cloned into pGL4.13 (Promega) to produce the recombinant vector pGL4.13/Slug 3'-UTR wt, which also contains the firefly luciferase ORF under the control of the SV40 promoter. Two miR-30a sites complementary to the GTTTAC sequence in the Slug 3'-UTR were mutated individually or in combination to remove complementarity to miR-30a using the QuikChange II XL site-directed mutagenesis kit (Stratagene, La Jolla, CA, USA) with pGL4.13/Slug 3'-UTR/wt as the template. The mutants were named Slug 3'-UTR/mut1 (single mutant), 3'-UTR/ mut2 (single mutant), and 3'-UTR/mut3 (double mutant). Supplementary Table S2 lists the primer sequences with mutated nucleotides underlined; also shown are the sequences of the mismatch primers used to generate the different Slug 3'-UTR mutants. MDA-MB-231 cells in 24well plates were co-transfected with $100 \mathrm{ng}$ Slug reporter construct containing wild-type or mutated 3'-UTR and pcDNA3 (control) or pcDNA3/miR-30a.

\section{Establishment of breast tumor cells stably expressing miR-30a}

Lentivirus carrying hsa-miR-30a (plemiR-30a) or control (plemiR) was packaged with a lentivirus expression system (Thermo Fisher Scientific) and the Trans-Lentiviral $^{\mathrm{TM}}$ GIPZ Packaging System (Open Biosystems, Huntsville, AL, USA). A puromycinresistant selectable marker was used to select against nontransduced cells to amplify miR-30a from the Hs578T and MDA-MB-231 cells.

\section{ChIP}

Chromatin from cell lines was sonicated and immunoprecipitated with rabbit polyclonal antibody against Slug or with rabbit IgG (negative control). The chemical cross-links were reversed by overnight incubation at $65^{\circ} \mathrm{C}$ in the presence of $8 \mathrm{M} \mathrm{NaCl}$, followed by the addition of proteinase $\mathrm{K}(10 \mathrm{mg} / \mathrm{mL})$ for $1 \mathrm{~h}$ at $45^{\circ} \mathrm{C}$ and RNase $(10 \mathrm{mg} / \mathrm{mL})$ for $30 \mathrm{~min}$ at $37^{\circ} \mathrm{C}$. After extraction and precipitation, DNA was dissolved in $30 \mathrm{~mL}$ of $\mathrm{ddH}_{2} \mathrm{O}$. Primers (Supplementary Table S2) were used to amplify specific sections of the 150-bp CLDN1, CLDN2, and $C L D N 3$ promoter regions that contain the predicted Slug binding sites. The PCR products were analyzed by $2 \%$ agarose gels and visualized with ethidium bromide staining.

\section{Invasion assay}

The cells were trypsinized and collected from dishes via brief centrifugation. Samples consisting of $5 \times 10^{4}$ cells were seeded into 48-well modified Boyden chambers 
(Neuro Probe, Cabin John, MD, USA) with $8-\mu$ m pore size polycarbonate membrane filters with Matrigel for $12 \mathrm{~h}$, and invading cells that were attached to the lower surface of the membrane were fixed with methanol and stained with Giemsa solution (Sigma-Aldrich Co., St Louis, MO, USA). Invading cells were quantified by counting five random high-power fields using an Olympus Ckx41 light microscope (Tokyo, Japan.).

\section{Confocal microscopy}

Cells were prepared for confocal laser scanning microscopy as described [34]. Cells were incubated separately with mouse anti-CLDN-1 (Invitrogen) or rabbit anti-CLDN-2 or anti-CLDN-3 (Novus Biologicals). For F-actin staining, cells were incubated with Alexa Fluor 488-conjugated phalloidin (Invitrogen) diluted in a blocking solution $(1: 40)$ for $20 \mathrm{~min}$. Nuclei were stained with 4',6'-diamidino-2-phenylindole (DAPI). The samples were examined under a confocal laser scanning microscope (Zeiss LSM 510 META, Jena, Germany) equipped with a UV laser $(351 / 364 \mathrm{~nm})$, an argon laser (457/488/514 nm), and a helium/neon laser $(543 \mathrm{~nm} / 633 \mathrm{~nm})$.

\section{Mouse xenotransplantation assay}

All mice were housed in the animal facility at the Chung Shan Medical University Experimental Animal Center, Taichung, Taiwan. Approval was obtained from the Institutional Animal Care and Use Committee of Chung Shan Medical University for the use of animals, and all experiments were performed in accordance with the guidelines for animal care of that committee. For the orthotopic implantation model, 6- to 8-week-old female $\mathrm{BALB} / \mathrm{c}$ nude mice were used. The mice were injected through the mammary fat pad with MDA-MB-231 breast tumor cells $\left(1 \times 10^{6}\right)$ suspended in Matrigel $(20 \% \mathrm{v} / \mathrm{v})$ (Becton-Dickinson, Franklin Lakes, NJ, USA) in PBS. The detailed procedure for measurement of tumor volume via an external caliper is described elsewhere [35]. In this way, primary tumors were measured on the days indicated in Figure 5, and tumor volume was calculated using the formula $1 / 2$ (length $\times$ width $^{2}$ ). In addition, the breast cancer lung metastasis model was established by tail-vein injection of MDA-MB-231 cells $\left(5 \times 10^{5}\right.$ cells in $0.1 \mathrm{~mL}$ of PBS). After 5 weeks, mice were sacrificed by $\mathrm{CO}_{2}$ asphyxiation. The number of metastatic lung tumors was confirmed with HE staining under a dissecting microscope.

\section{Laser-capture microdissection and quantitative real-time PCR}

All frozen tissue specimens were confirmed to be primary breast invasive ductal carcinoma based on their pathological features, and all the participants provided their written informed consent to participate in this study. Considerations regarding methodological issues in the present study, including research design, sampling scheme, and consent procedure, were approved by the Ethics Committee of the Institutional Review Board at the Chung Shan Medical University Hospital, Taichung, Taiwan. A detailed procedure for RNA isolation from cells collected by laser-capture microdissection is described elsewhere $[10,36]$. RNAs were extracted from lasercapture microdissection-collected samples of the tumor and the adjacent non-tumor breast tissue of each patient using the mirVana miRNA isolation kit (Ambion Inc., Austin, TX), and the RNA concentration in each sample was quantified on a NanoDrop 1000 spectrophotometer (NanoDrop Technologies, Waltham, MA). The singletube TaqMan miRNA assay (Applied Biosystems, Foster City, CA, USA) was used to detect and quantify mRNA expression on an Applied Biosystems instrument. Appropriate probes and primer sets were used to detect expression of genes encoding hsa-miR-30a (AB assay ID: 000417), FSCN (Hs00362704_m1), and CLDN2 (Hs01549234_m1) according to the procedure described by Applied Biosystems. Results were normalized against $G A P D H$ (for $F S C N$ and $C L D N 2$ ) and $R N U 6 B$ (for miR-30a). The relative expression of each mRNA, i.e., the $\mathrm{Ct}$ value, was calculated for the microdissected cells from the tumor and paired non-tumor tissues using the comparative CT method [10].

\section{Immunohistochemistry}

Detailed procedures for the immunohistochemical assays and scoring system are described elsewhere [36, 37]. Briefly, each tissue slide was reacted with monoclonal antibodies against Slug (Cell Signaling Technology); fascin (Santa Cruz Biotechnology); or CLDN-1, -2, or -3 (Novus Biologicals) in a humidified chamber for $60 \mathrm{~min}$ at $37^{\circ} \mathrm{C}$. Afterwards, the sections were washed with PBS and treated with an appropriate biotin-conjugated secondary antibody for $30 \mathrm{~min}$. The signal for each tissue section was detected using the avidin-biotin complex system and diaminobenzidine kit (Vector Laboratories, Burlingame, CA, USA). Immunohistochemical staining was quantified according to the coverage area and intensity for Slug as described [38]. The scoring system for the CLDNs and fascin is described elsewhere [39], with the following modifications: -, no staining or membrane staining in $<10 \%$ of tumor cells; + , faint, weakly perceptible positive staining of the membrane in $<10 \%$ of tumor cells; ++, weak-to-moderate complete membrane staining observed in $\geq 10 \%$ of tumor cells; and +++ , strong, complete membrane staining in $\geq 10 \%$ of tumor cells.

\section{Statistical analysis}

Data are presented as the mean \pm SD. Statistical comparisons were performed using the Student's $t$-test to test any statistically significant difference in the results 
between the different test groups. Statistical significance of the experimental data grouped by one variable was assessed with an unpaired two-tailed Student's $t$-test or a one-way ANOVA followed by Dunnett's test. All statistical analyses were performed using SPSS version 17.0 (SPSS Inc., Chicago, IL, USA).

\section{GRANT SUPPORT}

This work was supported by research grant NSC 102-2628-B-040-002-MY3 from the Ministry of Science and Technology, Taipei, Taiwan, ROC. The funders had no role in study design, data collection and analysis, decision to publish, or preparation of the manuscript.

\section{CONFLICTS OF INTEREST}

The authors declare that they have no potential conflicts of interest.

\section{REFERENCES}

1. Jung HY, Fattet L, Yang J. Molecular Pathways: Linking Tumor Microenvironment to Epithelial-Mesenchymal Transition in Metastasis. Clin Cancer Res. 2015; 21: 962-968.

2. Micalizzi DS, Farabaugh SM, Ford HL. Epithelialmesenchymal transition in cancer: parallels between normal development and tumor progression. J Mammary Gland Biol Neoplasia. 2010; 15:117-134.

3. Orlando FA, Brown KD. Unraveling breast cancer heterogeneity through transcriptomic and epigenomic analysis. Ann Surg Oncol. 2009; 16:2270-2279.

4. Polyak K. Breast cancer: origins and evolution. J Clin Invest. 2007; 117:3155-3163.

5. Bartel DP. MicroRNAs: genomics, biogenesis, mechanism, and function. Cell. 2004; 116:281-297.

6. Ding X, Park SI, McCauley LK, Wang CY. Signaling between transforming growth factor beta (TGF-beta) and transcription factor SNAI2 represses expression of microRNA miR-203 to promote epithelial-mesenchymal transition and tumor metastasis. J Biol Chem. 2013; 288:10241-10253.

7. Vetter G, Saumet A, Moes M, Vallar L, Le Béchec A, Laurini C, Sabbah M, Arar K, Theillet C, Lecellier CH, Friederich E. miR-661 expression in SNAI1-induced epithelial to mesenchymal transition contributes to breast cancer cell invasion by targeting Nectin-1 and StarD10 messengers. Oncogene. 2010; 29:4436-4448.

8. Bullock MD, Sayan AE, Packham GK, Mirnezami AH. MicroRNAs: critical regulators of epithelial to mesenchymal (EMT) and mesenchymal to epithelial transition (MET) in cancer progression. Biol Cell. 2012; 104:3-12.
9. Katoh Y, Katoh M. Hedgehog signaling, epithelial-tomesenchymal transition and miRNA (review). Int J Mol Med. 2008; 22:271-275.

10. Cheng CW, Wang HW, Chang CW, Chu HW, Chen CY, Yu JC, Chao JI, Liu HF, Ding SL, Shen CY. MicroRNA30a inhibits cell migration and invasion by downregulating vimentin expression and is a potential prognostic marker in breast cancer. Breast Cancer Res Treat. 2012; 134:1081-1093.

11. van Horssen R, Hollestelle A, Rens JA, Eggermont AM, Schutte M, Ten Hagen TL. E-cadherin promotor methylation and mutation are inversely related to motility capacity of breast cancer cells. Breast Cancer Res Treat. 2012; 136:365-377.

12. Kumarswamy R, Mudduluru G, Ceppi P, Muppala S, Kozlowski M, Niklinski J, Papotti M, Allgayer H. MicroRNA-30a inhibits epithelial-to-mesenchymal transition by targeting Snai1 and is downregulated in nonsmall cell lung cancer. Int J Cancer. 2012; 130:2044-2053.

13. Shih JY, Yang PC. The EMT regulator slug and lung carcinogenesis. Carcinogenesis. 2011; 32:1299-1304.

14. Dhasarathy A, Phadke D, Mav D, Shah RR, Wade PA. The transcription factors Snail and Slug activate the transforming growth factor-beta signaling pathway in breast cancer. PLoS One. 2011; 6:e26514.

15. Runkle EA, Mu D. Tight junction proteins: from barrier to tumorigenesis. Cancer Lett. 2013; 337:41-48.

16. Martínez-Estrada OM, Cullerés A, Soriano FX, Peinado H, Bolós V, Martínez FO, Reina M, Cano A, Fabre M, Vilaró S. The transcription factors Slug and Snail act as repressors of Claudin-1 expression in epithelial cells. Biochem J. 2006; 394:449-457.

17. Olson MF, Sahai E. The actin cytoskeleton in cancer cell motility. Clin Exp Metastasis. 2009; 26:273-287.

18. Li A, Morton JP, Ma Y et al. Fascin is regulated by slug, promotes progression of pancreatic cancer in mice, and is associated with patient outcomes. Gastroenterology. 2014; 146:1386-1396.

19. Tomaskovic-Crook E, Thompson EW, Thiery JP. Epithelial to mesenchymal transition and breast cancer. Breast Cancer Res. 2009; 11:213.

20. Liu Z, Chen L, Zhang X, Xu X, Xing H, Zhang Y, Li W, Yu H, Zeng J, Jia J. RUNX3 regulates vimentin expression via miR-30a during epithelial-mesenchymal transition in gastric cancer cells. J Cell Mol Med. 2014; 18:610-623.

21. Liu Z, Tu K, Liu Q. Effects of microRNA-30a on migration, invasion and prognosis of hepatocellular carcinoma. FEBS Lett. 2014; 588:3089-3097.

22. Huang J, Yao X, Zhang J, Dong B, Chen Q, Xue W, Liu D, Huang Y. Hypoxia-induced downregulation of miR-30c promotes epithelial-mesenchymal transition in human renal cell carcinoma. Cancer Sci. 2013; 104:1609-1617.

23. Zhang K, Chen D, Jiao X, Zhang S, Liu X, Cao J, Wu L, Wang D. Slug enhances invasion ability of pancreatic cancer 
cells through upregulation of matrix metalloproteinase-9 and actin cytoskeleton remodeling. Lab Invest. 2011; 91:426-438.

24. Machesky LM, Li A. Fascin: Invasive filopodia promoting metastasis. Commun Integr Biol. 2010; 3:263-270.

25. Vignjevic D, Kojima S, Aratyn Y, Danciu O, Svitkina T, Borisy GG. Role of fascin in filopodial protrusion. J Cell Biol. 2006; 174:863-875.

26. Iorio $\mathrm{MV}$, Ferracin $\mathrm{M}$, Liu $\mathrm{CG}$ et al. MicroRNA gene expression deregulation in human breast cancer. Cancer Res. 2005; 65:7065-7070.

27. Nassa G, Tarallo R, Giurato G, De Filippo MR, Ravo M, Rizzo F, Stellato C, Ambrosino C, Baumann M, Lietzèn N, Nyman TA, Weisz A. Post-transcriptional regulation of human breast cancer cell proteome by unliganded estrogen receptor beta via microRNAs. Mol Cell Proteomics. 2014; 13:1076-1090.

28. Zhu H, Wu H, Liu X, Li B, Chen Y, Ren X, Liu CG, Yang JM. Regulation of autophagy by a beclin 1-targeted microRNA, miR-30a, in cancer cells. Autophagy. 2009; 5:816-823.

29. Zou Z, Wu L, Ding H, Wang Y, Zhang Y, Chen X, Chen X, Zhang CY, Zhang Q, Zen K. MicroRNA-30a sensitizes tumor cells to cis-platinum via suppressing beclin 1-mediated autophagy. J Biol Chem. 2012; 287:4148-4156.

30. Zhong M, Bian Z, Wu Z. miR-30a suppresses cell migration and invasion through downregulation of PIK3CD in colorectal carcinoma. Cell Physiol Biochem. 2013; 31: 209-218.

31. Zhang N, Wang X, Huo Q, Sun M, Cai C, Liu Z, Hu G, Yang Q. MicroRNA-30a suppresses breast tumor growth and metastasis by targeting metadherin. Oncogene. 2014; 33:3119-3128.

32. Ouzounova M, Vuong T, Ancey PB, Ferrand M, Durand G, Le-Calvez Kelm F, Croce C, Matar C, Herceg Z, Hernandez-Vargas H. MicroRNA miR-30 family regulates non-attachment growth of breast cancer cells. BMC Genomics. 2013; 14:139.
33. Nichols LA, Grunz-Borgmann EA, Wang X, Parrish AR. A role for the age-dependent loss of alpha (E)-catenin in regulation of $\mathrm{N}$-cadherin expression and cell migration. Physiol Rep 2014; 2:pii,e12039.

34. Chu HW, Cheng $\mathrm{CW}$, Chou WC, Hu LY, Wang HW, Hsiung CN, Hsu HM, Wu PE, Hou MF, Shen CY, Yu JC. A novel estrogen receptor-microRNA 190a-PAR-1-pathway regulates breast cancer progression, a finding initially suggested by genome-wide analysis of loci associated with lymph-node metastasis. Hum Mol Genet. 2014; 23 : 355-367.

35. Euhus DM, Hudd C, LaRegina MC, Johnson FE. Tumor measurement in the nude mouse. J Surg Oncol. 1986; 31:229-234.

36. Cheng CW, Liu YF, Yu JC, Wang HW, Ding SL, Hsiung CN, Hsu HM, Shieh JC, Wu PE, Shen CY. Prognostic significance of cyclin D1, beta-catenin, and MTA1 in patients with invasive ductal carcinoma of the breast. Ann Surg Oncol. 2012; 19:4129-4139.

37. Cheng CW, Yu JC, Wang HW, Huang CS, Shieh JC, Fu YP, Chang CW, Wu PE, Shen CY. The clinical implications of MMP-11 and CK-20 expression in human breast cancer. Clin Chim Acta. 2010; 411:234-241.

38. Hasan MR, Sharma R, Saraya A, Chattopadhyay TK, DattaGupta S, Walfish PG, Chauhan SS, Ralhan R. Slug is a predictor of poor prognosis in esophageal squamous cell carcinoma patients. PLoS One. 2013; 8:e82846.

39. Lee TK, Poon RT, Man K, Guan XY, Ma S, Liu XB, Myers JN, Yuen AP. Fascin over-expression is associated with aggressiveness of oral squamous cell carcinoma. Cancer Lett. 2007; 254:308-315.

40. Singletary SE, Connolly JL. Breast cancer staging: working with the sixth edition of the AJCC Cancer Staging Manual. CA Cancer J Clin. 2006; 56:37-47. 